OPEN ACCESS

Edited by:

Johnny Kao,

Good Samaritan Hospital Medical

Center, United States

Reviewed by:

Michael Wayne Epperly,

University of Pittsburgh, United States

Christopher Paul Cifarelli,

West Virginia University Hospitals,

United States

*Correspondence:

Mark De Ridder

Mark.DeRidder@uzbrussel.be

Specialty section:

This article was submitted to

Radiation Oncology,

a section of the journal

Frontiers in Oncology

Received: 20 August 2021

Accepted: 08 October 2021

Published: 27 October 2021

Citation:

de Mey S, Dufait I and De Ridder M (2021) Radioresistance of Human Cancers: Clinical Implications of Genetic Expression Signatures.

Front. Oncol. 11:761901. doi: 10.3389/fonc.2021.761901

\section{Radioresistance of Human Cancers: Clinical Implications of Genetic Expression Signatures}

\author{
Sven de Mey, Inès Dufait and Mark De Ridder* \\ Department of Radiotherapy, Universitair Ziekenhuis Brussel, Vrije Universiteit Brussel, Brussels, Belgium
}

Although radiotherapy is given to more than $50 \%$ of cancer patients, little progress has been made in identifying optimal radiotherapy - drug combinations to improve treatment efficacy. Using molecular data from The Cancer Genome Atlas (TCGA), we extracted a total of 1016 cancer patients that received radiotherapy. The patients were diagnosed with head-and-neck (HNSC - 294 patients), cervical (CESC - 166 patients) and breast (BRCA - 549 patients) cancer. We analyzed mRNA expression patterns of 50 hallmark gene sets of the MSigDB collection, which we divided in eight categories based on a shared biological or functional process. Tumor samples were split into upregulated, neutral or downregulated mRNA expression for all gene sets using a gene set analysis (GSEA) pre-ranked analysis and assessed for their clinical relevance. We found a prognostic association between three of the eight gene set categories (Radiobiological, Metabolism and Proliferation) and overall survival in all three cancer types. Furthermore, multiple single associations were revealed in the other categories considered. To the best of our knowledge, our study is the first report suggesting clinical relevance of molecular characterization based on hallmark gene sets to refine radiation strategies.

Keywords: radiotherapy, TCGA (The Cancer Genome Atlas Program), gene set analysis, prognostic, head and neck (H\&N) cancer, cervical cancer, breast cancer

\section{INTRODUCTION}

Radiotherapy (RT) represents an essential treatment modality in cancer management, either alone or combined with other therapies. Approximately $50 \%$ of all cancer patients will receive radiotherapy at some time in their illness, resulting in a cure rate of about $40 \%$ (1). Over the past few decades, technological advances and clinical research have given radiation oncologists the capability to personalize treatments for accurate delivery of radiation dose based on clinical parameters and anatomical information (2). However, individual responses to RT vary widely among disease types and patient populations (3). The resistance to RT is associated with several biological alterations of the tumor cells and the tumor microenvironment (4). Unravelling the processes and hallmarks of cancer cells that lead to radioresistance will provide critical insights for future research into combination therapies with radiotherapy.

A detailed understanding of the cellular pathways involved in the response to irradiation is imperative to pave the way to more individualized RT. The last 20 years, precision medicine has harnessed genetic profiling's power to personalize cancer treatments, nonetheless similar 
predictions regarding tumor benefit following RT are lagging (5). Prior studies have examined associations between genotype and clinical radiosensitivity; DNA repair pathway alterations such as deleterious germline and somatic mutations in genes such as BRCA1, BRCA2, PALPB2, and ATM have been studied extensively as potential biomarkers of radiation sensitivity (6). Next to this, several clinically relevant associations have been described between epigenetics, hormone axis, receptor tyrosine kinase (RTK) signaling, intracellular signaling, the tumor microenvironment and radioresistance (7). Although these studies often identify genomic features that are known to be prognostic, translating these findings into actionable treatment decisions remains a significant challenge $(7,8)$.

To comprehensively evaluate clinically relevant genetic signatures, which may function as therapeutic targets of different cancer types, we integrated and analyzed clinical information and mRNA-sequencing data from head-and-neck (HNSC), cervical (CESC) and breast cancer (BRCA) patients that underwent radiotherapy. First, we selected the 50 hallmark gene expression signatures from the molecular signature database collection (MSigDB) (9). Each hallmark in this collection consists of a "refined" gene set, derived from multiple "founder" sets, that conveys a specific biological state or process and displays coherent expression. Using the comprehensive molecular and clinical data compiled in The Cancer Genome Atlas (TCGA) (10), we associated the upregulation or downregulation of these 50 hallmark gene expression signatures with the patients' clinical outcome. This approach allowed to divide the patients in the three different groups based on their respective gene expression levels (upregulated, neutral or downregulated) and correlated these groups with the patients' clinical outcome. To the best of our knowledge, our study is the first report suggesting clinical relevance of molecular characterization based on hallmark gene sets to refine radiation strategies.

\section{RESULTS}

\section{Patient Characteristics}

To investigate the clinically relevant molecular features of cancers with regard to survival following radiotherapy, we selected three relevant cancers: head-and-neck squamous cancer (HNSC), cervical squamous cancer (CESC), and breast (BRCA) cancer. HNSC comprises the sixth leading cancer diagnosis and includes a heterogeneous group of malignant tumors arising in all structures of the head-and-neck region, except for the brain, spinal cord, skull base, and skin. Patients with limited disease (T1-2N0) are treated by surgery or radiotherapy, according their general condition and functional implication of the treatment. Patients with locally advanced HNSC undergo surgery, followed by adjuvant chemoradiotherapy or radiotherapy alone. If these patients are not amenable to surgery they are treated by primary (chemo)radiation (11). CESC is the fourth most common female malignancy worldwide (12). Low stage CESC patients are treated with either surgery or RT. Concurrent chemotherapy with RT is given as adjuvant therapy for high-risk stages I to IIA. In stages IB, IIA-B, III, and IVA, concurrent chemotherapy with RT is given as primary therapy. For both HNSC and CESC the prognostic impact of tumor oxygenation during radiotherapy has been described in several retrospective studies. BRCA is a highly heterogeneous disease and the most common neoplasm in women. Although classic histopathologic classification of breast cancer remains important, molecular characterization of the disease is rapidly emerging as a vital tool for understanding clinical prognosis. Noninvasive and early invasive BRCA are usually treated with breast conserving surgery following adjuvant RT. Depending on TNM-stage, hormone receptor markers, HER2-status, differentiation grade, proliferation markers, ... are early invasive BRCA patients also treated with (neo)adjuvant radio(chemo)therapy (11). We chose these cancer types to offer a general overview of the 50 hallmark gene sets' influence on survival of patients who underwent RT.

We extracted data from all the 299 HNSC, 168 CESC and 549 BRCA patients that underwent radiotherapy in The Cancer Genome Atlas (TCGA) Pan-Cancer cohort. Their characteristics are shown in Table 1. Human Papillomavirus (HPV) negative (-) was the most common subtype in HNSC patients. At the same time, most of the CESC were squamous carcinomas and the majority of BRCA patients had a Luminal A subtype. The patient's age ranged from 19 to 90 , with the HNSC patients being the oldest (median 59.34), followed by the BRCA patients (median 56.71) and the CESC patients (median 48.89). The majority of patients were female and of the white race. All genetic data was taken from patients after they underwent surgery, but before the patients underwent adjuvant (chemo) radiotherapy. RT treatment schedules were as follows; HNSC patients received a median of $62 \mathrm{~Gy}$ with a treatment duration of 45 days. CESC patients received a median of 40Gy with 31.5 days of treatment and BRCA patients received 60Gy with a treatment time of 43 days. BRCA patients displayed the most extended overall survival (OS) and disease-free survival (DFS) (median OS: 32.48, DFS: 31.3), followed by CESC patients in OS (26.01) and DFS (26.79) time and HNSC patients presented with the shortest survival time (OS: 22.59, DFS: 22.42).

\section{Genetic Expression Subtypes Show Clinically Relevant Patterns}

To assess the heterogeneity of the different hallmark expression gene sets across the three cancer types, we used the computational method developed by Peng et al. (13). First, we extracted the $\mathrm{z}$-score ranked RNAseq data of each tumor sample for the above-described cancer patients. Z-scored data is RNAseq data normalized across samples by $\mathrm{Z}$ score to obtain a rank value for each gene. Next, we conducted a GSEA analysis, using the hallmark expression gene sets, on the resulting rank values to classify tumors into three subtypes: upregulated, neutral or downregulated $(14,15)$. The method derives its power by focusing on gene sets, that is, groups of genes that share a common biological function, chromosomal location, or regulation. Tumor samples for which the hallmark expression genes showed enrichment with high $\mathrm{Z}$ scores were defined as an upregulated subtype. In contrast, samples showing the opposite pattern were defined as downregulated subtype. Samples belonged to the neutral subtype when they did not show a 
TABLE 1 | Patient characteristics.

\begin{tabular}{|c|c|c|c|}
\hline & HHSC & CESC & BRCA \\
\hline No. of cases & 299 & 168 & 549 \\
\hline \multicolumn{4}{|l|}{ Subtype } \\
\hline HPV- & $228(76.8)$ & & \\
\hline HPV+ & $50(16.7)$ & & \\
\hline Adeno Carcinoma & & $23(13.7)$ & \\
\hline Squamous carcinoma & & $131(78)$ & \\
\hline Basal & & & 89 (10.7) \\
\hline HER2 & & & $33(6)$ \\
\hline LumA & & & $253(46.1)$ \\
\hline LumB & & & 98 (17.9) \\
\hline Normal & & & $17(3.1)$ \\
\hline HA & $21(7)$ & $14(8.3)$ & $59(10.7)$ \\
\hline Age (mean +-SOf & $59.34+-10.64$ & $48.89+-14.28$ & $56.71+-12.13$ \\
\hline Sex $M / F$ & $231 / 68$ & $0 / 168$ & $4 / 545$ \\
\hline \multicolumn{4}{|l|}{ Stage } \\
\hline I & $8(2.7)$ & & $92(16.8)$ \\
\hline II & $10(6)$ & & $280(51)$ \\
\hline III & $36(12.7)$ & & $160(29.1)$ \\
\hline IV & 184(61.5) & & $8(1.5)$ \\
\hline $\mathbf{x}$ & & & $6(1.1)$ \\
\hline HA & $51(17.1)$ & $168(100)$ & $3(0.5)$ \\
\hline \multicolumn{4}{|l|}{ TNM } \\
\hline T1/T2/T3/T4/TX/TIS/NA & $22 / 60 / 57 / 113 / 34 / 0 / 13$ & $56 / 48 / 16 / 5 / 11 / 1 / 31$ & $149 / 301 / 84 / 14 / 1 / 0 / 0$ \\
\hline N0/N1/N2/H3/NX/NA & $76 / 42 / 122 / 2 / 43 / 14$ & $54 / 36 / 0 / 0 / 47 / 31$ & $220 / 192 / 78 / 52 / 7 / 0$ \\
\hline M0/M1/MX/NA & $129 / 0 / 45 / 125$ & $53 / 8 / 75 / 32$ & $453 / 9 / 87 / 0$ \\
\hline \multicolumn{4}{|l|}{ Ethnicity } \\
\hline Hispanic or latino & $13(43)$ & $10(6)$ & $25(4.6)$ \\
\hline Hot hispanic or latino & $265(88.6)$ & $78(46.4)$ & $427(77.8)$ \\
\hline NA & $21(7)$ & $80(47.6)$ & $97(17.7)$ \\
\hline \multicolumn{4}{|l|}{ Race } \\
\hline \multicolumn{4}{|l|}{ American Indian or Alaska native } \\
\hline & $2(0.7)$ & $1(0.6)$ & $1(0.2)$ \\
\hline Asian & $6(2)$ & $5(3)$ & $10(1.8)$ \\
\hline Black, or African American & $28(9.4)$ & $17(10.1)$ & $98(17.9)$ \\
\hline White & $256(85.6)$ & $123(732)$ & $398(72.5)$ \\
\hline HA & $7(2.3)$ & $22(131)$ & $42(7.7)$ \\
\hline Dose (Gy) (median -IQR) & $62(60-66)$ & $40(27-45)$ & $60(50-60.4)$ \\
\hline Treatment days (median-IQR) & $45(41-52)$ & $31.5(18.75-42.25)$ & $43(32-47)$ \\
\hline Overall survival & 22.59 (13.69 - 41.72) & $26.01(16.17-48.67)$ & $32.48(18.6-63.3)$ \\
\hline \multicolumn{4}{|l|}{ (Months) (median-IQR) } \\
\hline Disease free survival Months (median -IQR) & $22.42(12.92-41.85)$ & $26.79(16.83-53.59)$ & $31.3(18.21-59.67)$ \\
\hline
\end{tabular}

significant enrichment pattern. Note that the concept of "upregulated" or "downregulated" here is relative to other tumor samples within the same cancer type, rather than relative to normal tissues (Figure 1A). We divided the 50 hallmark expression gene sets into eight categories based on their shared overlapping biological or functional process, namely Radiobiological, Metabolic, Proliferation, Development, Signaling, Cellular component, Pathway and Immune (Supplementary Table 1). We are aware that certain gene sets can be allocated into different categories, for example the G2M Checkpoint gene set into the proliferation category instead of the Radiobiological category, as genes often exert their functions on multiple levels. The eight described categories were based upon the proposed division of MSigDB and subsequently adapted to our own notion (9).

To assess the clinical relevance of the expression subtypes identified above, we determined associations with patient's OS using a Kaplan - Meier analysis, since survival represents a critical clinical index of tumor aggressiveness. Figure 1B shows the summary of 24 significant survival associations for the 50 hallmark expression gene sets associated with one of the three cancer types. Only 45 of the 50 hallmark gene sets are depicted, since there were no survival associations for the Apical Surface, Complement, Inflammatory response, Myogenesis and WNT Beta Catenin Signaling gene sets. At first glance, CESC patient's survival was associated with more hallmark gene sets than the other two cancer types. Most of the significant associations across cancer types are related to upregulated gene sets. Since we look for a link between these different gene signatures and survival, we cannot exclude that we are measuring intrinsic aggressiveness of the tumors, sensitivity to chemotherapy or other features that can influence the prognosis of the patients, next to radiosensitivity. However, the hallmark gene sets represent specific well-defined biological states or processes and display coherent expression. Also, this gene set collection has been thoroughly validated (9). 
A

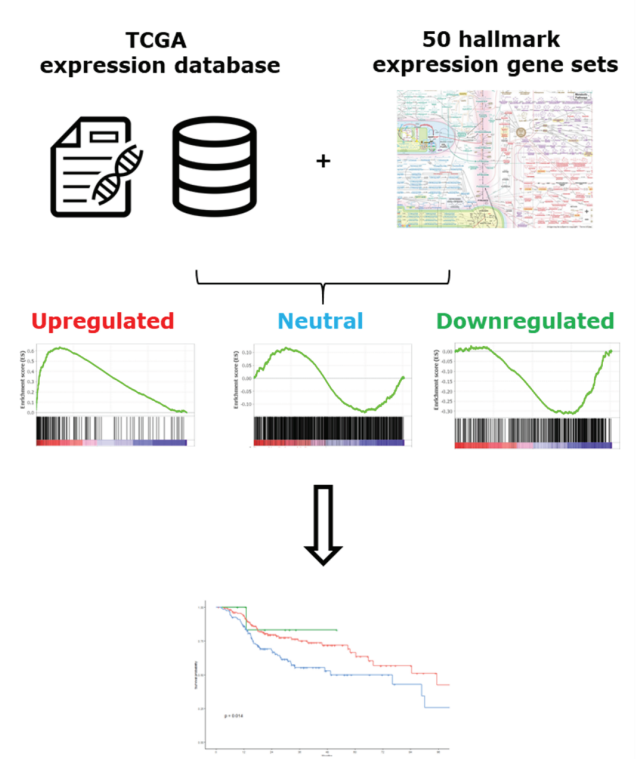

B

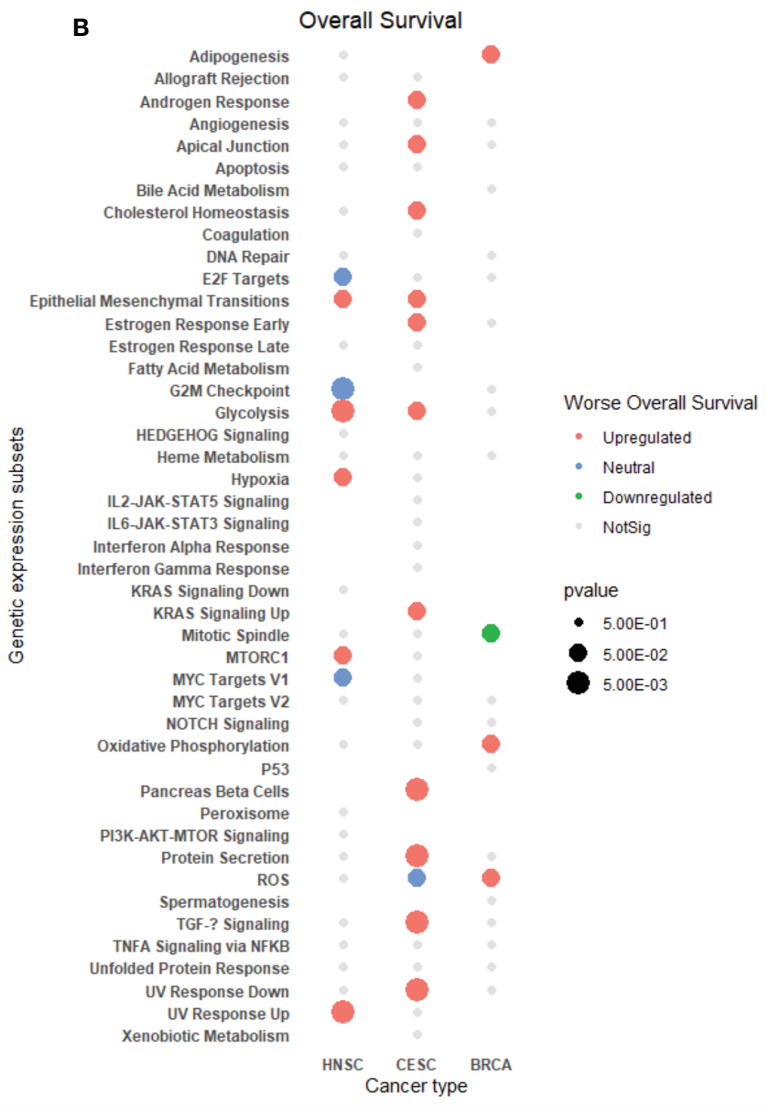

C

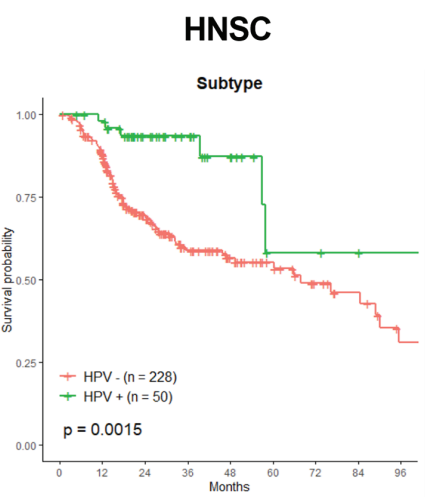

CESC

subtype

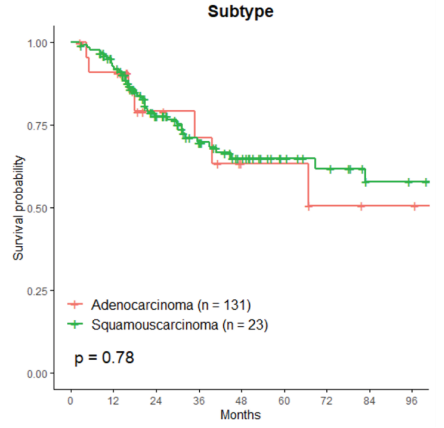

BRCA

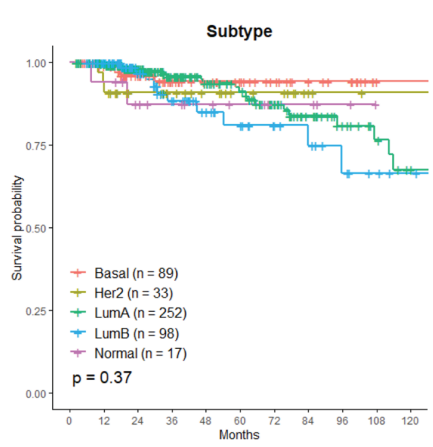

FIGURE 1 | Classification and association of gene set expression signatures with patient survival times and tumor subtypes. (A) The computational method to classify tumor samples into three expression subtypes: upregulated, neutral and downregulated. These subtypes were than associated with patient OS. (B) Clinical associations of gene set expression signatures with patient OS. Color indicates correlation direction and size the level of p-value (log-rank test). Grey dots were not significant and had $\mathrm{p}$-value lower than 0.5. Blanc spots were not significant for association with OS and had a p-value higher than 0.5. (C) Kaplan-Meier plots for molecular subtypes of HNSC, CESC and BRCA associated with patient overall survival times.

Specific tumor subtypes are identified in a clinical setting, as those tumor subtypes that are informative about cancer pathophysiology and are, in some cases, used for clinical decision making. For example, targeted therapies based on molecular targets such as BCR-ABL inhibitors in leukemia (16), BRAF and MEK inhibitors in melanoma $(17,18)$ and therapies targeting epidermal growth factor receptor (EGFR) in lung cancer and head-and-neck cancer patients (19) have significantly impacted the cancer treatment landscape. Therefore, we first examined whether these known clinical tumor subtypes influenced the survival of patients who underwent radiotherapy. Figure 1C shows the survival curves of each tumor type per cancer. In our analysis, only a statistically significant difference between HPV- and HPV + HNSC patients 
could be observed. HPV+ cancer patients who underwent radiotherapy displayed a better survival than HPV- negative cancer patients, which was already demonstrated in recent research $(20,21)$. There was no significant survival difference between adeno- or squamous-carcinoma CESC patients, which is not surprising considering the small number of patients with squamous cell carcinoma. The absence of a difference between the molecular BRCA cancer subtypes may be explained by the variety of specific adjuvant treatment strategies that are delivered ranging from anti-hormonal therapy and anti-HER2-antibodies to (dose-dense) chemotherapy.

\section{Radiobiological Category}

The radiobiological category incorporated six gene sets, namely: Hypoxia, G2M Checkpoint, Reactive Oxygen Species (ROS), UV Response Down, UV Response Up and DNA Repair. We clustered these gene sets because each of them has a direct link with radioresistance. Already since the 1950s, it was known that hypoxic cancer cells were more resistant to ionizing radiation. Measured by polarographic oxygen electrode, the oxygenation status in CESC, HNSC and soft tissue sarcomas has been proven to be an adverse prognostic factor for radiotherapy $(22,23)$. These measurements were performed in tumors that were treated with primary radiotherapy. According to our analysis, in a post-operative setting, upregulation of the hypoxia gene set had a negative association with OS for HNSC (Figure 2A, p = 0.014 ) and a negative (non-significant) trend for CESC (Figure 2B, $\mathrm{p}=0.078$ ) patients, but not for BRCA patients (Figure 2C, $\mathrm{p}=0.64$ ). Surprisingly, was there an association for the HNSC and CESC patients and not for the BRCA patients, since all three patients groups were irradiated postoperatively to eliminate lingering cancer cells, which evidently are not subjected to hypoxic conditions.

In general, cells are the most sensitive to radiotherapy in the G2 or M phase of the cell cycle (24-27). Successful research has been performed by combining inhibitors of the G2M checkpoint arrest with radiotherapy (28-32). Only for HNSC patients, the upregulation and downregulation of the G2M gene set was associated with better survival (Figure 2D, $\mathrm{p}=0.00042$ ). HNSC patients with an upregulated G2M gene had a survival benefit for the first two years; afterwards the survival curve converged with the curve of the reference (neutral) patient group (Figure 2D).

ROS causes approximately two-thirds of radiation-induced DNA damage, so cancer cells' capability to detoxify ROS has an impact on their radiosensitivity $(22,33)$. Research has shown that increased expression or activity of antioxidant enzymes was correlated with poor radioresponse (34-36). Upregulation of the ROS gene set (genes that are upregulated by ROS, meaning genes activated by oxidative stress or responsible for antioxidant activity) was associated with better OS in CESC patients (Figure 2E, p = 0.0056), while upregulation had a negative association with OS for BRCA patients (Figure 2F, p = 0.037).

The three last gene sets were related to DNA damage and in what way cancer cells can respond. DNA is the primary target of radiation and its damages are the prime source of the biological effects of radiation $(24,37,38)$. UV response (down and up) involved the downregulated or upregulated genes after cells were radiated with UV radiation. The DNA repair gene set incorporates the genes involved in DNA repair. The upregulation of the UV Response Down gene set was associated with worse survival in CESC (Figure 2G, $\mathrm{p}=0.001$ ). For HNSC patients, the upregulation of the UV Response Up gene set was associated with worse OS (Figure 2H, p =0.0039) Neither upregulation nor downregulation of the DNA Repair gene set was associated with OS in any of the three cancer types.

To summarize the generated data per gene set, we calculated the cox proportional hazard ratios for every gene set (Figure 2I). The hazard ratio describes the probability of death of a patient, while the KM curves estimate the survival function. For the KM, a $\log$ rank test is used to test the hypothesis that different populations' survival curves do not differ. The upregulation of the hypoxia gene set in HNSC was associated with an increased risk of death (Figure 2I, HR: 1.77). Both upregulation and downregulation of the G2M gene set were associated with a reduced risk of death in HNSC patients (Figure 2I, HR-up: 0.58; HR-down: 0.24). The upregulation of the ROS gene set was associated with a higher risk of death in BRCA (HR: 1.87) but displayed a reduced risk of death in CESC patients (HR: 0.41) (Figure 2I). CESC patients with an upregulation of the UV Response Down gene set were associated with three times higher risk of death (Figure 2I, HR: 3.06) and HNSC patients with an upregulation of the UV Response Up gene set were associated with a higher risk of death (HR: 1.80) (Figure 2I). In line with the KM curves, neither upregulation nor downregulation of the DNA repair gene set were associated with any hazard ratio.

\section{Metabolism Category}

The metabolism category exist of seven gene sets: Glycolysis, Oxidative Phosphorylation (OXPHOS), Fatty Acid Metabolism, Cholesterol Homeostasis, Heme Metabolism, Xenobiotic Metabolism and Bile Acid Metabolism. Metabolic reprogramming of cancer cells is considered one of the hallmarks of cancer $(39,40)$. Increasing evidence suggests that metabolic reprogramming in cancer is one of the major factors contributing to radioresistance (41-43).

Alterations in the glycolytic metabolism in cancer influences radioresponses and extensive research has been performed to develop molecules or inhibitors of several glycolytic targets (44, 45). In our analysis, the upregulation of the Glycolysis gene set was associated with a worse OS in HNSC (Figure 3A; $\mathrm{p}=0.00023$ ) and CESC (Figure 3B; $\mathrm{p}=0.015$ ), while no association was found for BRCA patients (Figure 3C; $p=0.47$ ).

Although rewiring energy metabolism in cancer is mostly associated with a switch from OXPHOS to glycolysis (46), research demonstrates that cancer cells can use a wide range of energetic profiles and OXPHOS represents a major source of energy production (47). Recent evidence links the upregulation of OXPHOS or metabolic plasticity to increased radioresistance in oesophageal adenocarcinoma, breast, pancreatic and head and neck cancer (48-51). There appeared to be non-significant trend (in the first months) of better OS in HNSC when OXPHOS was downregulated (Figure 3D; $\mathrm{p}=0.093$ ), while in CESC there appeared to be a non-significant trend of better OS when OXPHOS was upregulated (Figure 3E; p $=0.066$ ). 
A

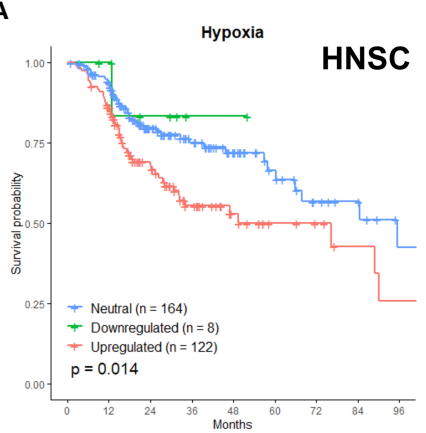

C

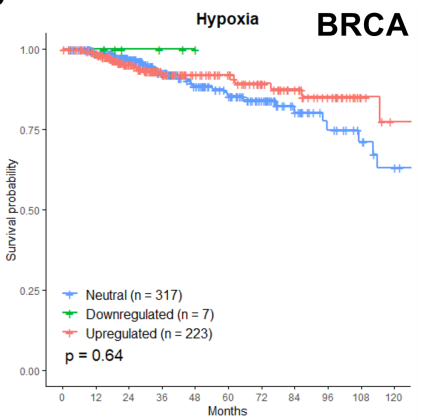

E

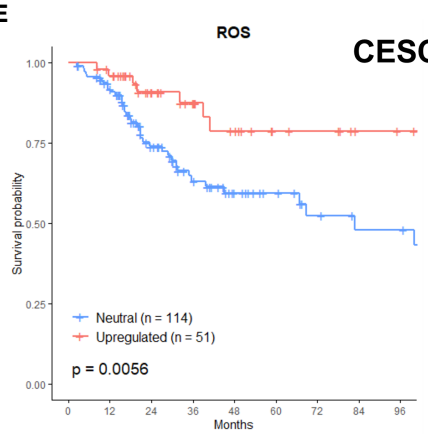

G

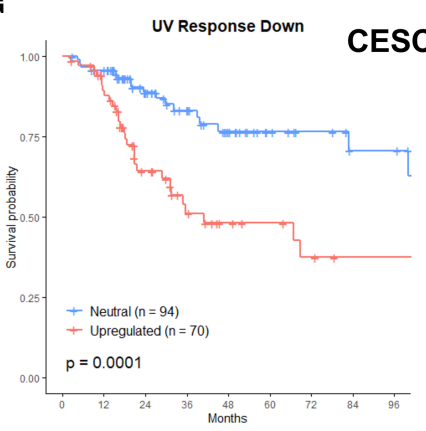

B

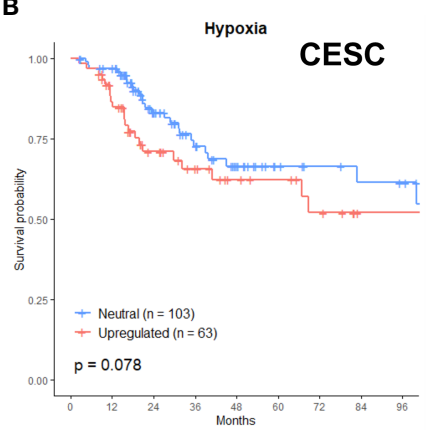

D

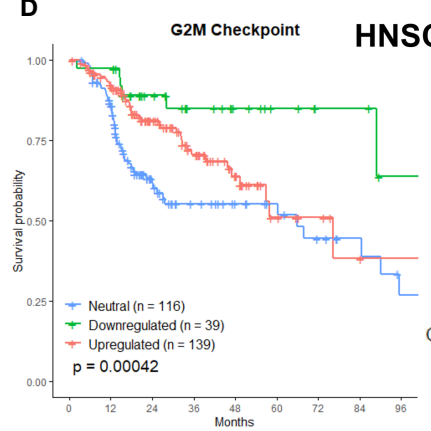

HNSC

1

Overall Survival

$F$

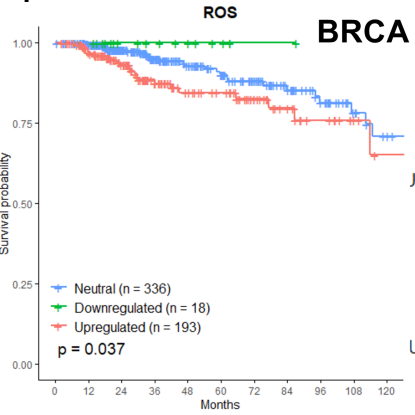

H

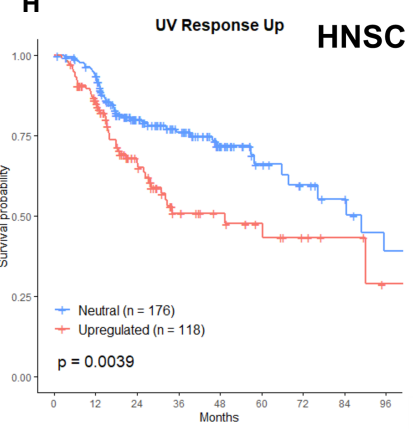

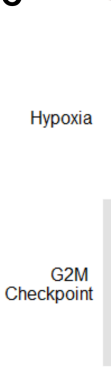

verall Surviva
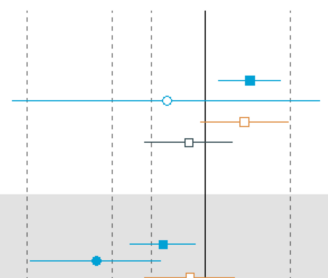

int

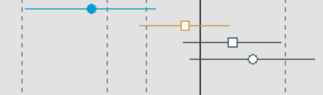

Ros

ROS

UV Response

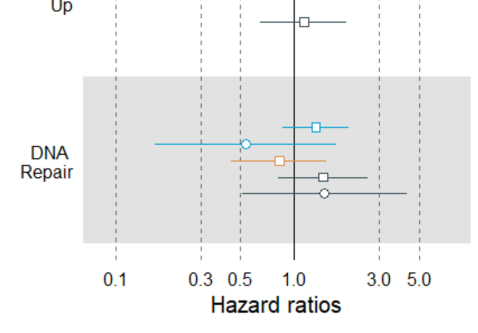

Cancer $\bullet$ HNSC $\bullet$ CESC $\bullet$ BRCA

Category • Downregulated घ Upregulated

FIGURE 2 | Associations of gene sets of the Radiobiological category with patient overall survival times. Kaplan-Meier plots for the Hypoxia gene set of (A) HNSC, (B) CESC and (C) BRCA patients associated with OS. (D) Kaplan-Meier plot for the G2M Checkpoint gene set of HNSC patients associated with OS. Kaplan-Meier plots for the ROS gene set for (E) CESC and (F) BRCA patients associated with OS. (G) Kaplan-Meier plot for the UV Response Down gene set for CESC patients associated with OS. (H) Kaplan-Meier plot for the UV Response Up gene set for HNSC patients associated with OS. (I) Forest plot showing the results from CoxPH model fits for OS of all the Radiobiological category gene sets. Results for the HNSC patients are in blue, brown for the CSC patients and black for the BRCA patients. Upregulated gene sets are depicted with a $\square$ symbol [closed $\mathbf{\square}$ means these results are significant $(\mathrm{p}>0.05)$ ]. Downregulated gene sets are depicted with a O symbol [closed $\bullet$ means these results are significant $(p>0.05)$ ]. 
A

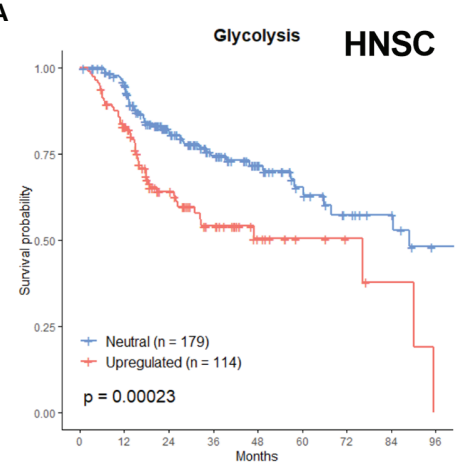

D

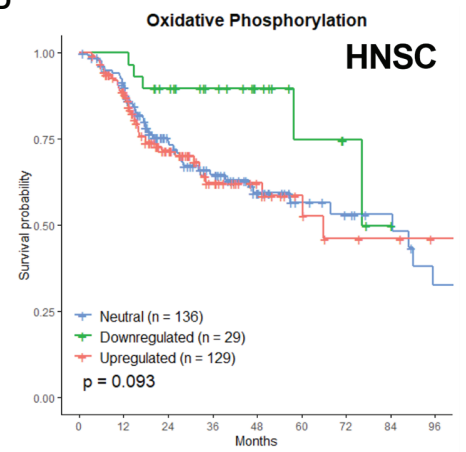

F

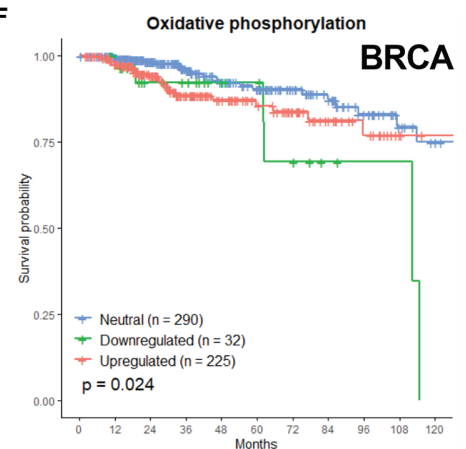

H

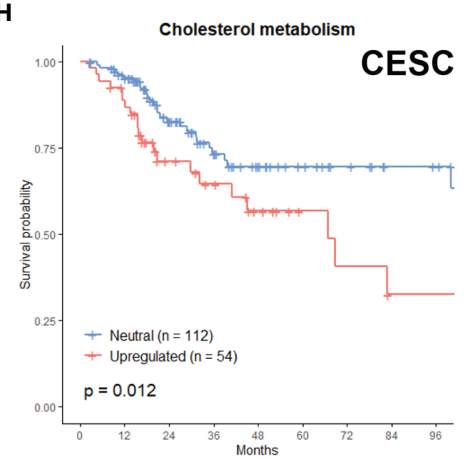

B

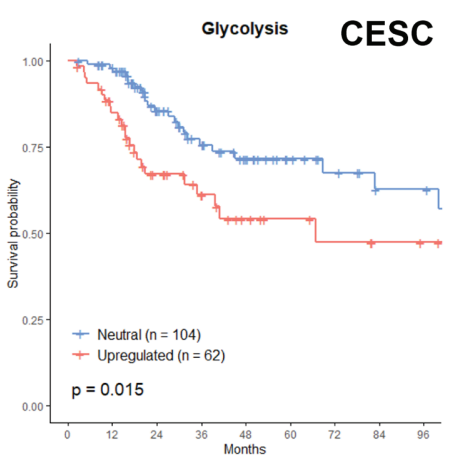

E
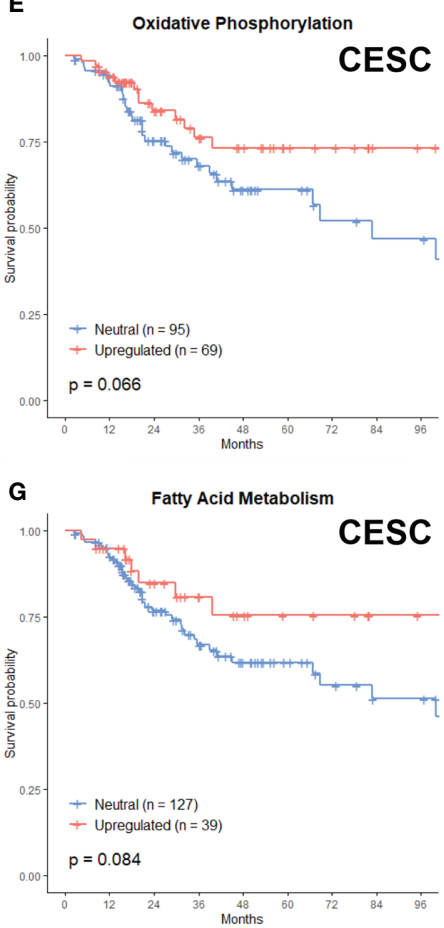

'

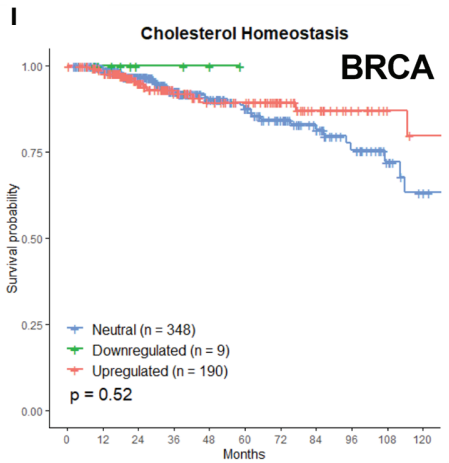

C

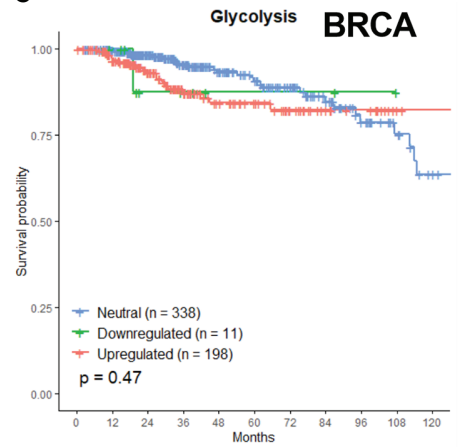

J

Overall Survival

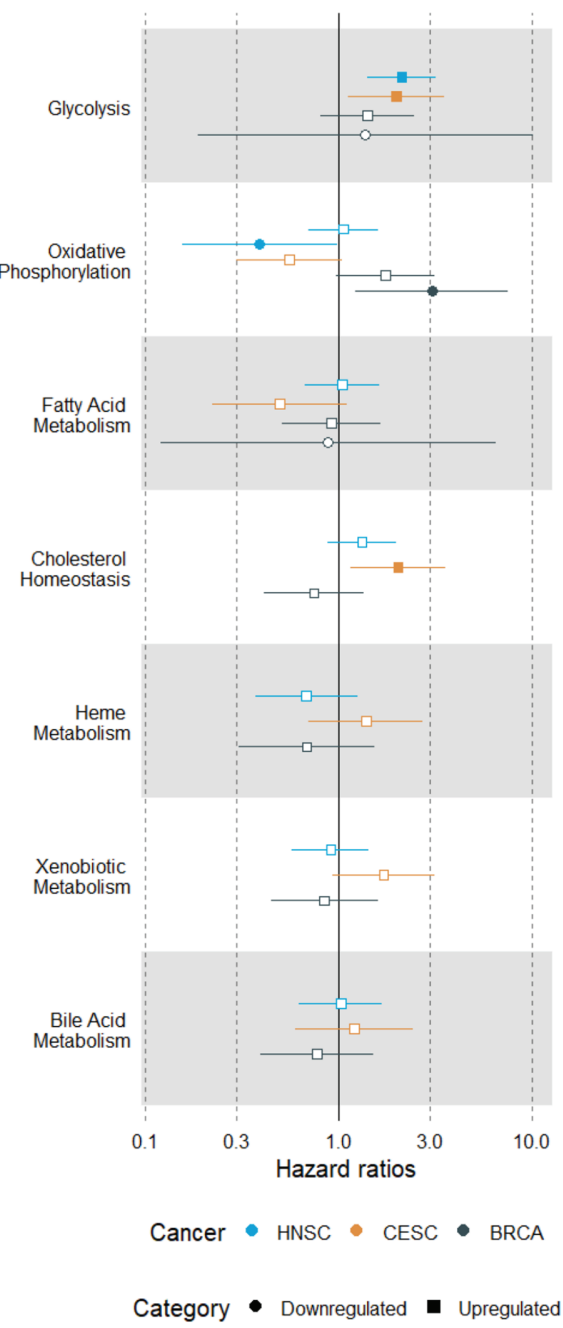

FIGURE 3 | Associations of gene sets of the Metabolism category with patient overall survival times. Kaplan-Meier plots for the Glycolysis gene set of (A) HNSC, (B) CESC and (C) BRCA patients associated with OS. Kaplan-Meier plots for the Oxidative Phosphorylation gene set of (D) HNSC patients, (E) CESC patients and (F) BRCA patients associated with OS. (G) Kaplan-Meier plot for the Fatty Acid gene set for CESC associated with OS. Kaplan-Meier plots for the Cholesterol gene set for (H) CESC patients and (I) BRCA patients associated with OS. (J) Forest plot showing the results from CoxPH model fits for OS of all the Metabolism category gene sets. Results for the HNSC patients are in blue, brown for the CSC patients and black for the BRCA patients. Upregulated gene sets are depicted with a $\square$ symbol [closed means these results are significant $(p>0.05)$ ]. Downregulated gene sets are depicted with a $O$ symbol [closed means these results are significant $(p>0.05)]$. 
Downregulation of OXPHOS in BRCA patients was associated with worse OS (Figure 3F; p =0.024). Many cancers show an upregulated lipogenesis (52) and recent research linked this with enhanced radioresistance in prostate cancer and breast cancer cells (53-56). Nonetheless, no significant association was found for the Fatty Acid Metabolism gene set in any of the cancer types, however upregulation appeared to be associated with better OS in CESC patients (Figure 3G).

Cholesterol is vital for the survival and growth of mammalian cells. It is a membrane constituent and a precursor to bile acids and steroid hormones, which can initiate and promote colon, breast and prostate cancers (57). Targeting cholesterol metabolism with statins in clinical studies for cancer patients suggested an added benefit for patient survival across various cancer types (58-63). In combination with radiation, statins can improve clinical outcomes via their radiosensitizing properties. However, the available clinical data is conflicting $(64,65)$. Here, upregulation of the Cholesterol Homeostasis gene set was associated with worse OS for CESC patients (Figure $3 \mathbf{H} ; \mathrm{p}=$ 0.012). For BRCA patients, no association was found (Figure $\mathbf{3 H}$; $\mathrm{p}=0.52)$

The critical role of heme in mitochondrial respiration and ADP/ATP exchange presumably explains how heme plays a pivotal role in fueling tumor cells' proliferation. However, only a small amount of research has been performed regarding the role of heme metabolism and radioresistance. It has been proven that expression of heme oygenase is linked with response to radiotherapy in nasopharyngeal carcinomas (66). In solid tumors, the extracellular and intracellular distribution of drugs exhibits a high degree of variability, is largely controlled by Drug and xenobiotic metabolizing enzymes (DXME) and influx and efflux systems that transport drugs into and out from cells. Expression of DXME within tumor cells is known to play a role in tumor cell survival and in tumor-specific absorption, distribution, metabolism, and excretion (ADME) of drugs (67). Cancer cell drug resistance or sensitivity is critically impacted by expression of DMXE within tumors. Understanding which specific DXME contributes to response to particular drugs will lead to better precision medicine $(68,69)$. However, no research has been done in combination with radiotherapy. Bile acids are physiological detergent molecules synthesized from cholesterol exclusively in the liver (70-72). Bile acids itself have been implicated in the development of hepatocellular, bile duct and colon cancer (73-75). Research has mainly been performed to develop novel therapeutic approaches to treat cholestasis and inflammation-related liver diseases $(72,76)$. Upregulation or downregulation of the Heme Metabolism, Xenobiotic and Bile Acid Metabolism gene sets had no significant difference in survival (Data not shown).

Hazard ratio's are again in line with the Kaplan-Meier curves. The risk of death for HNSC (HR: 2.13) and CESC (HR: 2.0) patients with an upregulated Glycolysis gene set was enhanced (Figure 3J). Downregulation of the OXPHOS gene set was associated with a lower risk of death in HNSC patients (Figure 3J; HR: 0.39). In contrast, this was associated with a higher risk of death in BRCA patients (Figure 3J; HR: 3.06).
For the Fatty acid gene set, no associations were found (Figure 3J). In CESC patients, the upregulation of the Cholesterol Homeostassis gene was associated with a higher risk of death (Figure 3J, HR: 2.04). Lastly, upregulation or downregulation of the Heme Metabolism, Xenobiotic and Bile Acid Metabolism gene sets had no significant difference in survival or risk (Figure 3J).

\section{Proliferation Category}

The proliferation category incorporates gene sets that are involved in the cell cycle progression, nutrient signals necessary for proliferation and proper function of cells. The proliferation category contains six gene sets: E2F Targets, Mitotic Spindle, MTORC1 Signaling, Myc Targets V1, Myc Targets V2 and $\mathrm{P} 53$. We expected that tumors with an upregulated gene set from the proliferation category would exhibit a more aggressive phenotype with a worse prognosis.

E2Fs have emerged as major transcriptional regulators of cell cycle-dependent gene expression. E2F activity, as defined by expression of E2F target genes, is high in virtually all cancers, often owing to inactivation of its main binding partner and key regulator, $\mathrm{RB}$ (encoded by $\mathrm{RB} 1$ ), overexpression of cyclindependent kinases (CDKs) or inactivation of CDK inhibitors (77-79). The E2F family controls the transcription of cellular genes that are responsible for cell division (80). The expression pattern of E2F activators is abnormal in multiple human malignancies, such as ovarian cancer (81), breast cancer (82), bladder cancer (83), prostate cancer (84), lung adenocarcinoma (85) and colon cancer $(86,87)$. In conclusion, the E2Fs are a complex family of transcriptional regulators whose precise expression and activity are critical to protect cells from abnormal proliferation and cell cycle-generated genomic errors. So far, the E2Fs family has not yet been investigated as potential target for radiosensitization. Our analysis establish that downregulation of the E2F Targets gene set was associated with better OS in HNSC (Figure 4A; $p=0.027$ ). Although not significantly, we visually saw a trend of better OS with the upregulation of the E2F Targets gene of CESC patients (Figure 4B; $\mathrm{p}=0.17$ ) and no association was found in BRCA patients (Figure 4C; $\mathrm{p}=0.22$ ).

The mitotic spindle is essential for cell division by mitosis, so inhibition is an effective way to delay or stop exit from mitosis. Anti-mitotic drugs like taxanes and vinca alkaloids were clinically effective as anti-tumor compounds $(88,89)$ and a lot more are under development (90). Some clinical trials have combined these newer drugs with radiotherapy, but the focus is on combination with chemotherapy (91). For both upregulation and downregulation of the Mitotic Spindle gene set visually there appeared to be a non-significant trend with better OS in HNSC patients (Figure 4D, $\mathrm{p}=0.14$ ), while for CESC patients visually there appeared a non-significant trend (in the first 60 months) with worse OS for the upregulation(Figure 4E, $\mathrm{p}=0.24$ ). Downregulation of the Mitotic Spindle in BRCA was significantly associated with worse OS (Figure 4F, p=0.0069).

MTORC1 is key driver of cancer drug resistance, since it integrates a diverse set of environmental cues, from growth 
A
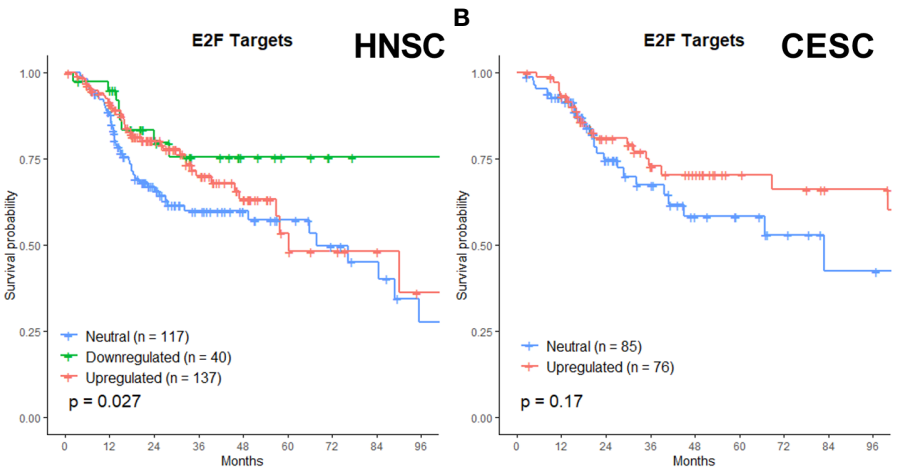
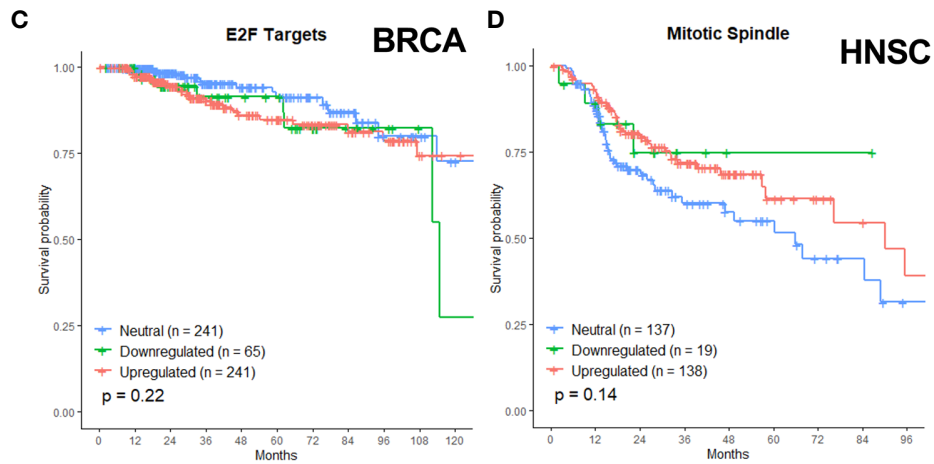

I

\section{Overall Survival}

E
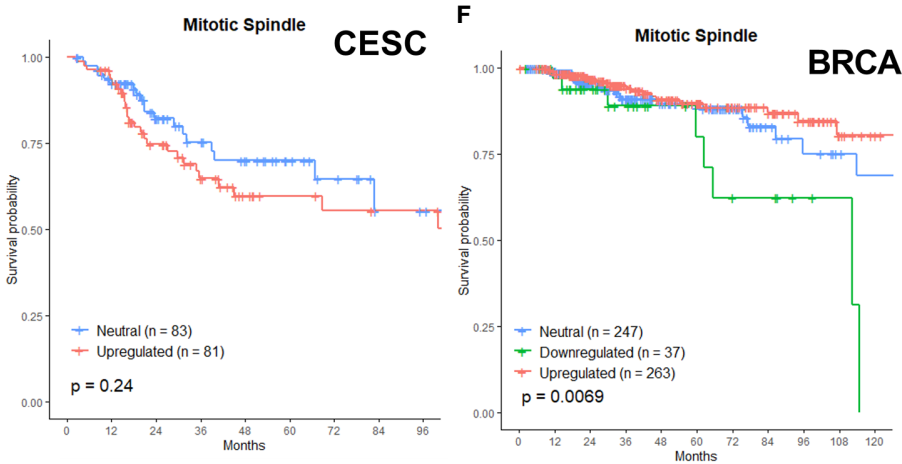

G

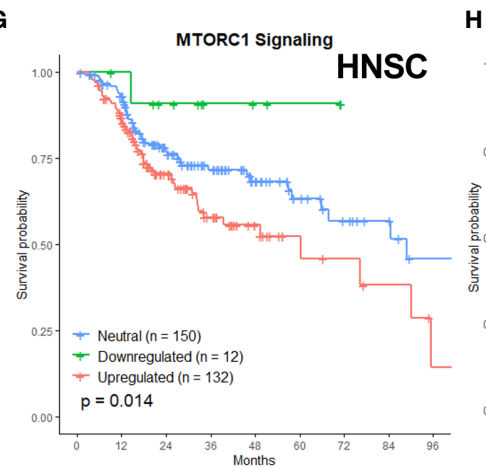

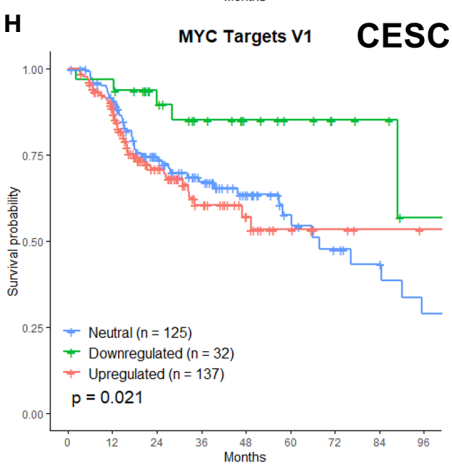
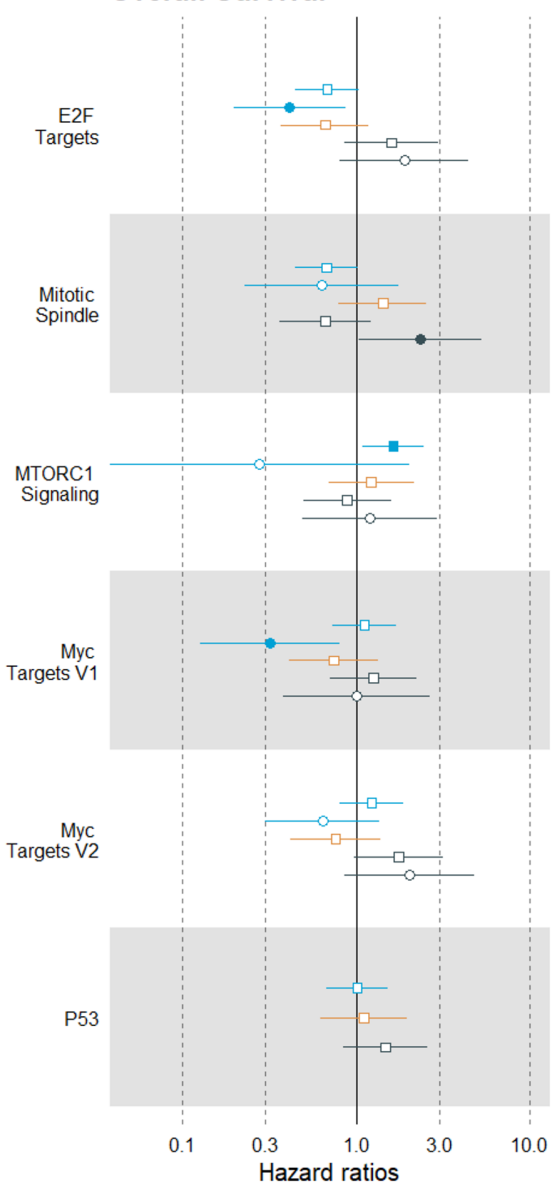

Cancer - HNSC - CESC - BRCA

Category • Downregulated

FIGURE 4 | Associations of gene sets of the Proliferation category with patient overall survival times. Kaplan-Meier plots for the E2F Targets gene set of (A) HNSC, (B) CESC and (C) BRCA patients associated with OS. Kaplan-Meier plots for the Mitotic Spindle gene set of (D) HNSC patients, (E) CESC patients and (F) BRCA patients associated with OS. (G) Kaplan-Meier plot for the MTORC1 gene set for HNSC associated with OS. (H) Kaplan-Meier plot for the MYC Targets V1 gene set for CESC patients associated with OS. (I) Forest plot showing the results from CoxPH model fits for OS of all the Proliferation category gene sets. Results for the HNSC patients are in blue, brown for the CSC patients and black for the BRCA patients. Upregulated gene sets are depicted with a $\square$ symbol [closed $\square$ means these results are significant ( $p>0.05)$ ]. Downregulated gene sets are depicted with a $\bigcirc$ symbol [closed - means these results are significant ( $>>0.05)]$. 
factor signals and nutritional status to direct metabolism and cell growth (92-95). Upregulation of MTROC1 signaling is also linked to enhanced radiotherapy resistance (96). Multiple groups have also demonstrated that the PI3K/AKT/mTOR pathway activation in response to radiotherapy is a principal mechanism of radioresistance $(97,98)$. Our data showed that upregulation of MTORC1 Signaling gene set was associated with worse OS in HNSC patients (Figure 4G, p = 0.014)

$\mathrm{MYC}$ is a master transcriptional regulator that controls almost all cellular processes. There is a wealth of data indicating that the deregulation of MYC activity occurs in many cancers and contributes to disease progression, metastatic potential, and therapeutic resistance $(99,100)$. Overexpressed c-Myc has also been found to promote radioresistance $(101,102)$. Only downregulation of the MYC Targets V1, and not MYC Targets V2, was associated with better OS in CESC patients (Figure $\mathbf{4 H}, \mathrm{p}=$ 0.021) MYC Targets V2 was not associated with OS in any of the three cancers (data not shown).

The transcription factor P53 is known as a key molecule for determining cellular responses to ionizing radiation by initiating a spectrum of cell-type specific responses, including cell cycle arrest, senescence, apoptosis and DNA damage repair $(103,104)$. It has been shown that p53 determines tissue-specific radiosensitivity and mutations of p53 can influence this radiosensitivity (105). Surprisingly, neither upregulation nor downregulation was associated with OS in any of the three cancers (data not shown).

Figure 4I shows the calculated HRs. In HNSC patients, the downregulation of the E2F Targets gene set was associated with a lowered risk of death by more than two-fold (Figure 4I, HR: 0.41). No association was found for CESC or BRCA patients. Downregulation of the Mitotic Spindle in BRCA patients showed a two-fold higher risk of death (Figure 4I, HR: 2.3). The upregulation of the MTORC1 Signaling gene set was only associated with a higher risk of death in HNSC patients (Figure 4I, HR: 1.63). MYC Targets V1 was associated with a lower risk of death in CESC patients (Figure 4I, HR: 0.32), while MYC Targets V2 was not associated with risk of death in any of the three cancers (Figure 4I). Upregulation or downregulation of the P53 gene set was not associated with death risk in any of the three cancers (Figure 4I).

\section{Other Expression Sets With Clinical Relevance}

The remaining categories of gene sets are the Development, Signaling, Cellular component and Pathway. Since only a small amount gene sets from the remaining categories have an association with OS in one of the three cancer types, we will not discuss all of them in detail but will only highlight the gene sets displaying an association with OS.

Most of the associations between the remaining gene sets and OS were found in CESC patients (Figures $\mathbf{5} \mathbf{A}-\mathbf{H}$ ). From the Development category we showed that upregulation of the Epithelial Mesenchymal Transition gene set (Figure 5A, p = 0.016) and upregulation of the Pancreas Beta Cell gene set (Figure 5B, p=0.0025) were associated with worse OS. The epithelial-mesenchymal transition (EMT) is an important step leading to invasion and migration of various cancer cells (106). Recently, more and more evidence has shown that EMT functions as an essential process involved in radioresistance (107-109). The Pancreas Beta Cell gene set incorporates genes that were specifically upregulated in pancreatic beta cells. In the signaling category, the upregulation of the Androgen Response (Figure 5C $\mathrm{p}=0.0071$ ), Estrogen Response Early (Figure 5D, $\mathrm{p}=0.008$ ), KRAS Signaling Up (Figure 5E, $\mathrm{p}=0.032$ ) and TGF- $\beta$ Signaling (Figure 5F, p $=0.00024$ ) were associated with worse OS. Androgens are expressed at different levels in men and women, and while they are important for proper development, they can also drive tumor growth. The role of the androgen receptor in prostate cancer has been extensively studied, but recent data suggest that androgen receptor signaling may also be important in breast cancer, glioblastoma, and additional tumor types (110, 111). One study found that significant subsets of gynecologic cancers express androgen receptors, which may have clinical relevance. Radiotherapy has been shown to induce Androgen receptor expression in prostate cancer cells, and androgen deprivation therapy sensitizes cancer cells to radiotherapy (112). Numerous studies have established a proof of concept that abnormal expression and function of estrogen receptors (ER) are crucial processes in initiation and development of hormonerelated cancers and affect the efficacy of anti-cancer therapy (113). Research is ongoing to resolve the complex situation that impedes the therapeutic efficiency of endocrine therapy and radiotherapy. The KRAS Signaling Up gene set incorporated the genes that were upregulated by KRAS activation. KRAS mutations have been linked to cellular and clinical radioresistance (114-119). However, KRAS mutant tumors comprise a heterogeneous group of cancers and reported mechanisms of cellular radioresistance appear highly variable, consistent with the notion of intertumoral heterogeneity $(116,120)$. In cervical cancer, the presence of KRAS mutations was an independent predictor of disease recurrence (121). Members of the TGF- $\beta$ family are key regulators of embryonic development, tissue homeostasis, and regeneration, and their malfunction has been implicated in cancer, fibrosis, immune diseases and many other pathologies (122). TGF- $\beta$ has been reported to be an endogenous, radiation-inducible radioresistance factor in some cancer cells while not affecting the radio-sensitivity in others. In addition, TGF- $\beta$ also regulates the transcription of various target genes responsible for the pathological changes of late radiation damage in the non-tumour-bearing tissues of previously irradiated patients $(123,124)$. Only one gene set from the cellular component category is associated with OS. Upregulation of the Apical Junction gene set is associated with worse OS in CESC patients (Figure 5G, p = 0.041). The apical junction complex is a cell-cell adhesion system present at the upper portion of the lateral membrane of epithelial cells integrated by the tight junction and the adherens junction. Research is just starting to understand the importance and therapeutic potential of apical junction complex proteins and their role in the early and late stages of cancer (125). Also in the pathway category is only one gene set associated with OS for CESC patients. Upregulation of 
CESC

A

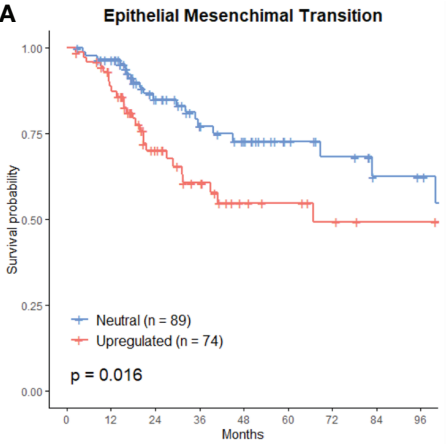

B

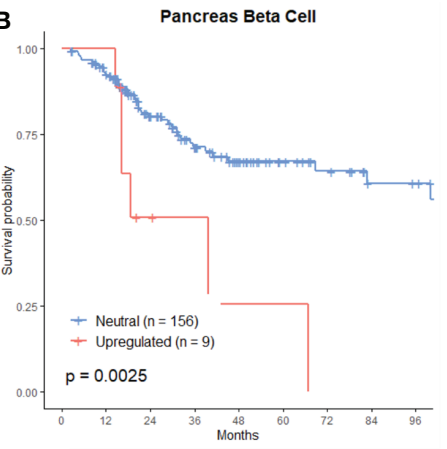

C

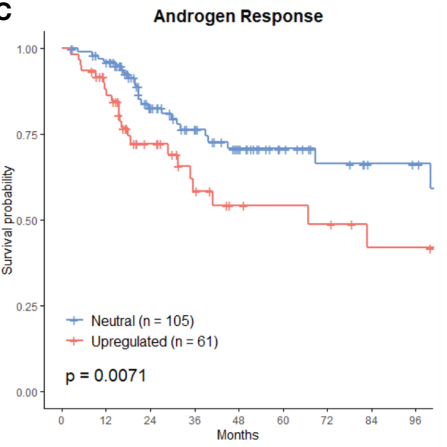

D

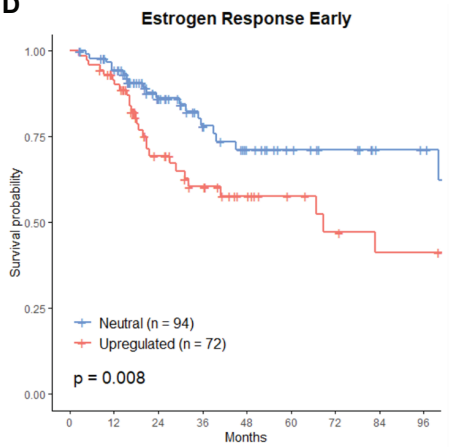

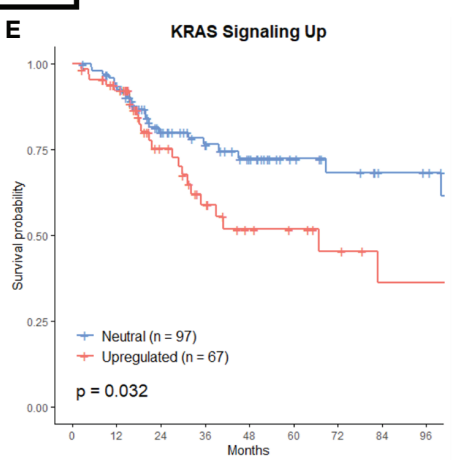

F TGF-ß Signaling

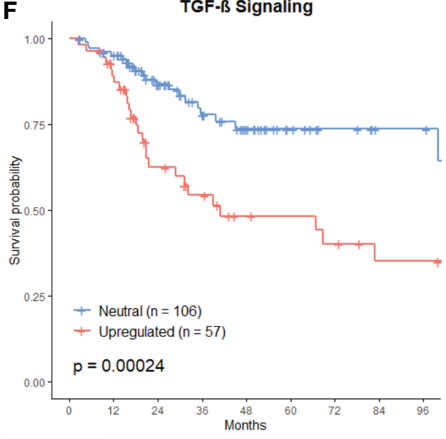

G

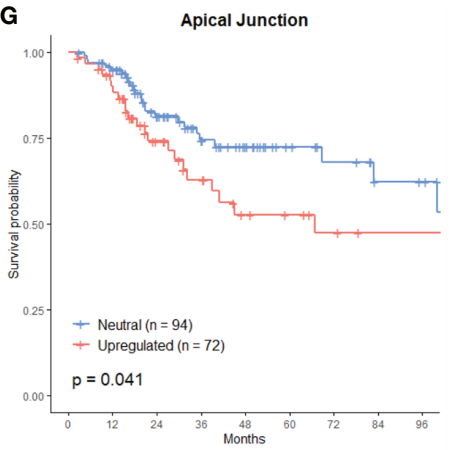

H

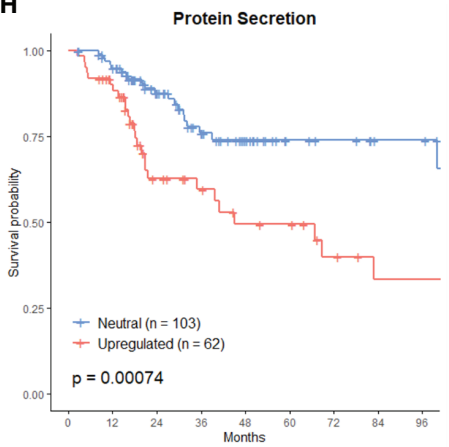

HNSC
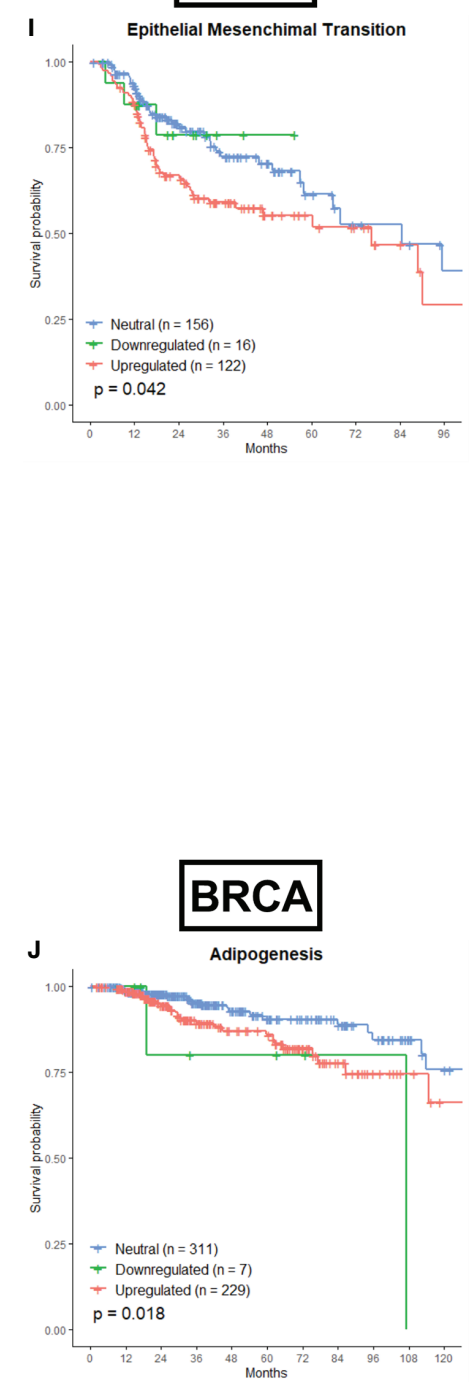

FIGURE 5 | Associations of gene sets of the Development, Signaling, Cellular Component and Pathway categories with patient overall survival times. Kaplan-Meier plots of CESC patients associated with OS for (A) the Epithelial Mesenchymal Transition gene set, (B) the Pancreas Beta Cell gene set, (C) the Androgen Response gene set, (D) the Estrogen Response Early gene set, (E) KRAS Signaling Up gene set, (F) TGF- $\beta$ Signaling gene set, (G) Apical Junction gene set and (H) Protein Secretion gene set. (I) Kaplan-Meier plot for the Epithelial Mensenchymal Transition gene set of HNSC patients associated with OS. (J) Kaplan-Meier plot for the Adipogenesis gene set of BRCA patients associated with OS. 
the Protein secretion gene set is correlated with worse OS (Figure 5H, p = 0.00074). The dysfunction of the secretory pathway is the cause of a variety of systemic and developmental diseases, like cancer, diabetes, Parkinson's disease, and congenital neurodegenerative disorders (126-129).

Only the upregulation of the EMT gene set was associated with worse OS in HNSC patients (Figure 5I, p=0.042). For BRCA cancer, the upregulation and downregulation of the Adipogenesis gene set (from the Development category) was associated with worse OS (Figure 5J, p = 0.018). It has already been proven that abnormal adipocyte metabolism is linked with radioresistance, mainly in BRCA $(130,131)$.

\section{Immune and Stromal Scores}

In our analysis, none of the immune gene sets were associated with better prognosis or survival. This was very unexpected, especially since there is a known relationship between immune cells and RT outcome $(132,133)$. Therefore, we opted to investigate this further and correlated the infiltration of immune cells (or other cells) with survival after radiotherapy. Using the ESTIMATE algorithm (134), immune infiltration scores were calculated and patients were divided into high or low immune scores with the median as cut-off. Next, we compared the survival of the two groups (Figures 6A, C, E). A high immune infiltration was significantly associated with better
A

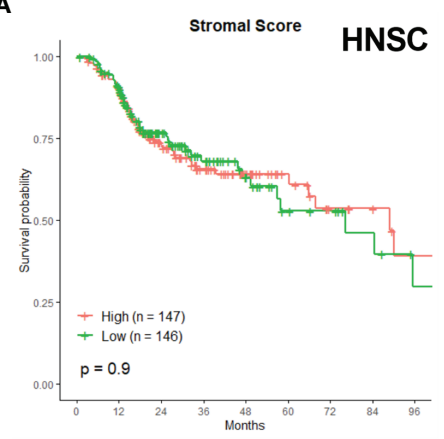

C

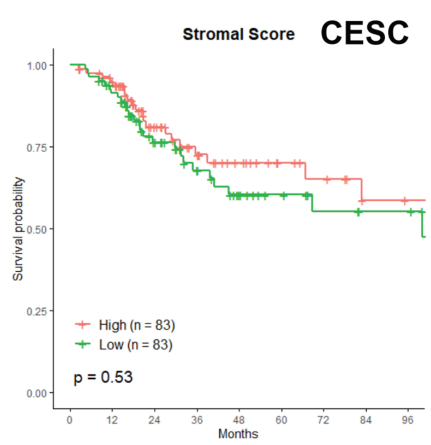

E

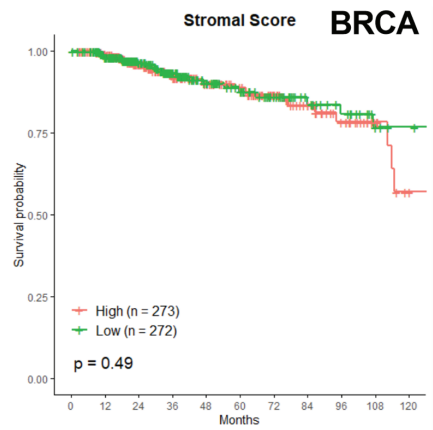

B

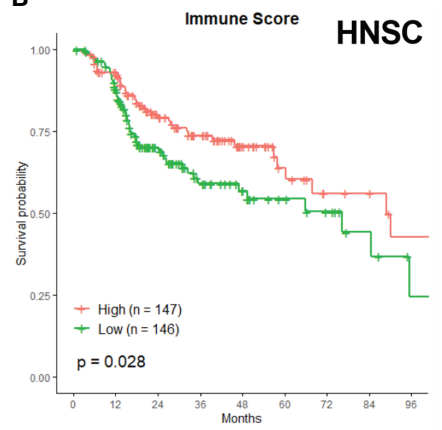

D

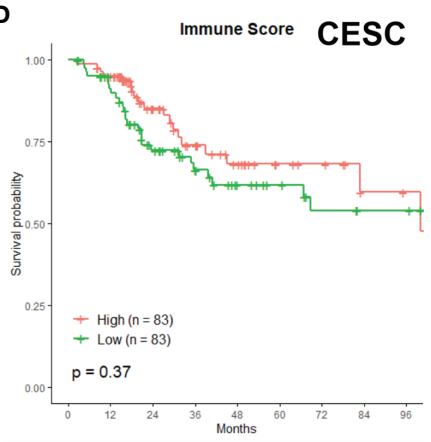

F

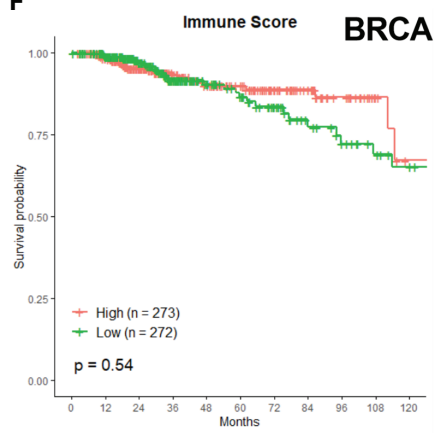

FIGURE 6 | Associations of Stromal and Immune score with patient overall survival times. Kaplan-Meier plots of OS of HNSC patients with (A) Stromal Score and (B) Immune Score. Kaplan-Meier plots of OS of CESC patients with (C) Stromal Score and (D) Immune Score. Kaplan-Meier plots of OS of BRCA patients with (E) Stromal Score and (F) Immune Score. 
OS in HNSC patients (Figure 6A), however this was not the case for CESC (Figure 6C) and BRCA (Figure 6E). Next to immune score, the stromal score was calculated using the ESTIMATE algorithm. This stromal score was developed to capture the presence of stromal cells in the tumor tissue. Again, no significant association of stromal score and OS was found for any of the three cancer types (Figures 6B, D, F).

\section{DISCUSSION}

More than $50 \%$ of all cancer patients are treated with radiotherapy at some point during their treatment. However, there is a lot of heterogeneity in the clinical responses to radiotherapy between different cancer types and even within the same cancer type. Resistance to radiotherapy is polymodal and associated with several biological alterations both within the tumor and the surrounding microenvironment. Radiosensitizers are needed to improve treatment response to radiation. Although the research into radiosensitizers already started 60 years ago, only a few radiosensitizers were implemented in the clinic. A wide range of obstacles, such as cancer stem cells, tumor heterogeneity, angiogenesis and vasculogenesis, metabolic alterations, drug-related adverse events, ... poses a significant challenge in increasing the efficacy of RT by radiosensitizers ( 7 , $135,136)$. In this study, we attempted to unravel potential radiosensitization targets in a more systematic and clinically relevant way. Based on HNSC, CESC and BRCA patient cohorts that underwent radiotherapy and their parallel mRNA data, we investigated 50 hallmark gene sets that describe essential processes and pathways and their impact on patient survival.

We anticipated four of the eight gene set categories to be highly predictive with regard to OS in patients who underwent RT, namely the Radiobiological, Metabolism, Proliferation and Immune category. The six gene sets from the Radiobiological category were chosen to represent known biological processes that influence cancer cells' radiosensitivity. Indeed, we observed that Hypoxia, G2M checkpoint and ROS gene sets were associated with OS in at least one of the three cancer types. Surprisingly, the other three gene sets related to cancer cells response to RT were overall not associated with OS. In recent years, researchers discovered that the metabolism of the cells also influences radiosensitivity and radioresistance. We observed that both Glycolysis and OXPHOS were associated with OS for one of the three cancer types. Extensive research has already been performed in developing molecules or inhibitors for several targets of glycolysis or OXPHOS and several clinical trials underway $(40,47)$. An interesting finding was the upregulation of the Cholesterol gene set associated with OS in CESC patients. The Cholesterol pathway has been successfully targeted with statins, however combinations with radiotherapy resulted in conflicting results (64), which should be further unravelled.

We expected that the gene sets from the Proliferation category would also be associated with OS in RT patients. These gene sets are involved in the cell cycle progression, nutrient signals necessary for proliferation, and cells' proper function.
We observed that downregulation of the E2F Targets was associated with better OS in HNSC. E2Fs are a complex family of transcriptional regulators and have not been investigated as a potential target for radiosensitization. Downregulation of the Mitotic Spindle gene set was associated with worse OS in BRCA. Several drugs are under development that target the mitotic spindle pathway. However, few have been tested in combination with radiotherapy (91). MTORC1 is a master regulator of cell growth and proliferation. Upregulation of the MTORC1 Signaling gene set was associated with worse OS in HNSC patients. Upregulation of the MTORC1 pathway has already been linked to enhanced RT resistance (96). MYC is a known oncogene and overexpressed c-MYC has been shown to promote radioresistance $(101,102)$. We observed that downregulation of the MYC Targets V1 was associated with better OS in CESC patients. Surprisingly, the P53 pathway was not correlated with OS in any of the three cancer types. It would be interesting to correlate outcomes of different gene sets with the expression of ki67 on the biopsies of the different tumors; unfortunately, this data is not available in the used databases. Ki67 is mainly expressed in actively proliferating cells and is a proliferationrelated nuclear antigen (137). Ki67 has been widely investigated as a potential prognostic maker of proliferation in retrospective studies of malignant diseases (138-141).

Several other gene sets from the remaining categories (Development, Signaling, Cellular Component and Pathway) were also associated with OS. In CESC patients, the EMT, the Pancreas Beta cell, Androgen Response, Estrogen Response Early, KRAS Signaling UP, TGF- $\beta$ Signaling, Apical Junction and the Protein secretion gene set was associated with OS. It is worth noting that the association of Androgen Response and Estrogen Response Early with OS in CESC patients was to be expected. Already in the 1970s, researchers linked sex hormones to genital cancer $(142,143)$. Several epidemiological studies have shown that multiple pregnancies and recent oral contraceptive use are potential cofactors of CESC (144). In addition, it was demonstrated that circulating levels of sex steroid hormone testosterone and possibly estradiol were positively involved in CESC (143, 145-147). Since androgens and estrogens are biochemically closely related, it is difficult to obtain solid evidence on whether they are separately or cooperatively involved in cervical carcinogenesis (145). For HNSC patients, only the upregulation of EMT gene set was associated with worse OS. For BRCA the upregulation and downregulation of the Adipogenesis gene set were associated with worse OS.

The most surprising results from this study occurred within the Immune category, where none of the examined gene sets were associated with better survival after RT. Merely a high immune score, a score for infiltrating immune cells, within HNSC correlated with better survival than a low immune score. The success of cancer immunotherapy has demonstrated that immune cells can be harnessed to eliminate tumor cells (148). It is becoming critical to understand the immune infiltration in the TME in the immunotherapy era to boost anti-tumor immunity further (131, 135). Furthermore, it has been shown that immune contexture (the density, functional orientation and location of immune cells) of the 
tumors is import for prediction of clinical outcome (149-152). Studies reported that HPV-related HNSC exhibited an increased immune infiltration in general compared with HPV-unrelated tumors (153). In CESC patients, tumor infiltration proved to be a superior prognostic factor compared to stromal lesions (154-156). Historically, BRCA has been regarded as an immunologically "cold" phenotype, however recent studies suggest potential in immunotherapeutic approaches to improve outcomes of specific subsets of BRCA patients $(148,157)$. RT has long been hypothesized to have actions complementary to those of immune checkpoint blockade, and a growing body of evidence indicates that cancer immunotherapy may also have radiosensitizing effects, which would provide unique benefits for loco-regional treatments (132). As a side note, we have to mention that no patient within our data set received CLTA4 or PD-1/PD-L1 inhibitors. The recent clinical success of these immunotherapies in different cancers suggest that these results should be interpreted with caution (158). It is possible that treating patients with immunotherapeutics could change the immune TME and lead to a better correlation with outcome. Nonetheless, in our study, we failed to show a survival benefit for any immune-related pathways but did demonstrate a better survival with a high immune score in HNSC.

Numerous research groups have used genomic-based approaches for the prediction of tumor response after RT. Most of these groups utilized high-throughput RNA expression technologies to develop gene expression signatures prognostic of low local recurrence risk or predictive of response to radiation treatment in the adjuvant setting for patients with early-stage disease. The initial studies where a correlation was described between gene expression and radiosensitivity were conducted in vitro on the NCI-60 panel of cancer cell lines. The best known are the studies where signatures of radiation sensitivity were identified using survival after 2Gy (SF2) or 8Gy (SF8) as a metric $(159,160)$. The group using the SF2 later developed the radiosensitivity index (RSI), which has been assessed in the clinic in various disease types, with varying levels of utility identified (161-165). Similar approaches were applied to identify radiosensitivity signatures and test them in Omnibus datasets or TCGA to create signatures for breast, head and neck, prostate, lung and glioma (166, 167).

In the latter cancer type, all patients receive radiotherapy as part of their treatment plan. As a consequence, the impact of radiotherapy on gene signatures has been extensively studied. Transcriptomic, methylation, mutational and mesenchymal signatures following radiotherapy all have been reported to correlate with patient's prognosis in glioblastoma (GBM) (168172). For example, gene signatures focusing on mesenchymal traits, which can be induced by radiation, distinctively correlate with worse prognosis (173). Within this present study, upregulation of the Epithelia Mesenchymal Transition gene set was only correlated with a worse prognosis in CESC patients, highlighting the importance of distinct approaches for each tumor type, and even tumor subtype. Additionally, GSEA was performed in an Omnibus GBM cohort and several cancer related pathways, such as p53 signaling pathway were enriched in the group with low OS (172).

The best-known genetic signature to predict radiation sensitivity across several different types of cancer is the panel of Torres-Roca et al. (174), which is based on the RSI. His team developed a calculation, called GARD (genomic-adjusted radiation dose), that uses the ten-gene panel to work out the biological dose based on an individual's radiation sensitivity. Other groups have used genomic studies to compare patientmatched pre-RT and post-RT tumors to obtain insight into clonal evolution in response to treatment and understand radioresistance mechanisms (175). For example, whole-exome sequencing before and after chemoradiotherapy showed that cooccurring KRAS/TP53 mutations in rectal cancers conferred a poor response, confirming the radioresistance associated with this genotype $(116,176,177)$. However, none of these signatures have been implemented into standard clinical settings and only give limited inside into the biological processes that underline radioresistance.

Our study contained several limitations. First, our research was based on gene expression of a single time-point. Gene expression analyses provide only a snapshot in time of the overall growth and treatment of the cancer. Keeping this in mind, the association between a particular gene set and survival can serve as a prognostic biomarker, even if this association neglects the influence of radiotherapy. A second limitation consists of a potential bias from variation in follow-up information in the TCGA database due to the retrospective nature of the TCGA cohort. Furthermore, in large public databases, such as TCGA, many sequenced disease states and settings do not include patients who received RT or offer adequate details concerning delivered RT schedules. Thirdly, is it possible that some gene expression profiles such as the metabolism or proliferation category not only correlate with radioresponse but also with the aggressiveness of the tumor. For example, it is well-established that metabolic reprogramming is linked with accelerated growth and proliferation of cancer cells $(39,178)$. Additionally, tumor aggressiveness between the three cancer types varies immensely. BRCA cancer patients, on average, display a more positive prognosis than HNSC or CESC patients. Better survival leads to fewer statistical events, which can influence the correlation with the investigated gene sets. Fourthly, all data is derived from patients receiving radiotherapy in an adjuvant setting post-surgery, potentially influencing the reported prognostic associations. Ideally, inclusion of data on neoadjuvant radiotherapy would be of great interest to complete this study. Sadly, many genomics studies lack radiation therapy treatment and outcome data, especially from neoadjuvant treatment, seriously limiting the data's clinical utility (179). Lastly, we studied all genes separately. It can be expected that interactions between the different gene sets may play a role as well. We are currently developing a dedicated random subspace decision forest analyses. This supervised learning algorithm would be able to select individual genes and specific interactions and thereby improve the prediction accuracy (180). Our study found that none of the 50 hallmark gene sets were associated with OS for all three cancer types simultaneously. We believe that part of this heterogeneity can be explained by the above-described limitations. 
However, our study's heterogeneity across the three tumor types also highlights the necessity to invest in more personalized treatment. The old paradigm of one-size-fits-all cannot apply across and intra-cancer types in this era. The need for a diverse array of diagnostic and therapeutic options employed in oncology reflects cancer heterogeneity in general. To optimize personalized precision medicine, it is essential to understand the complexity of the underlying interactions between biological tissue and RT. On the one hand, clinical studies including RT that pro-actively investigate different omics (molecular, metabolic and imaging data) are needed to capture relevant data. On the other hand, more advanced modelling techniques become necessary to predict radiotherapy responses in order to understand the underlying trends across populations. Coupling the relevant data with novel modeling techniques such as machine learning will enhance our capabilities to establish a tailored precision treatment scheme per patient, where drug radiotherapy combinations are put central.

To conclude, we have set up a clinically relevant approach using OS of HNSC, CESC and BRCA patients that underwent radiotherapy to associate with upregulation or downregulation of biological relevant hallmark gene sets. We established that 3 of the eight gene set categories, namely the Radiobiological, Metabolism and Proliferation, had predictive associations between several gene sets and OS. Surprisingly, we did not observe any associations between immune gene sets and OS in these patients cohorts. Interesting to note was the high heterogeneity across the three cancer types, which partly can be explained by the limitations of this study. However, this heterogeneity demonstrates that we need to opt for a tailored precision treatment scheme based on omics data. We believe that our study is the first step in this direction by using biologically relevant gene sets instead of single genes. However, there is a need for more databases or prospective studies that collect data from patients undergoing RT in a neo-adjuvant setting and capture RT outcome instead of survival. These databases or studies should go hand in hand with more complex modelling efforts to capture the complexity and interactions between the tumor and RT. Although we realise that a lot of work is still necessary, we believe this work can contribute to personalization of cancer treatment with regards to RT.

\section{MATERIALS AND METHODS}

\section{Gene Expression and Clinical Data}

mRNA expression (RNA Seq V2 RSEM) and associated clinical data were obtained from cBioPortal $(181,182)$ of all the HNSC (523), CESC (297) and BRCA (1084) patients of the TCGA PanCancer Atlas. The mRNA expression data were downloaded in the form of z-score-transformed data. We extracted patients who underwent radiotherapy using the R package "dplyr" and "stringr" from the clinical data. In total 294 HNSC, 166 CESC and 549 BRCA patients underwent radiotherapy. All patients underwent surgery followed with adjuvant (chemo)radiotherapy. Data on radiation scheme and dose were downloaded from the PanCancer Atlas website (183).

\section{MsigDB Hallmark Collection}

The molecular signature database (MsigDB) hallmark collection exists out of 50 hallmark gene sets. Hallmark gene sets summarize and represent specific, well-defined biological states or processes and display coherent expression. These gene sets were generated by a computational methodology based on identifying gene set overlaps and retaining genes that display coordinate expression. The hallmarks reduce noise and redundancy and provide a better delineated biological space for GSEA. Originally these 50 hallmark gene sets were divided into eight process categories: Cellular Component, Development, DNA damage, Immune, Metabolic, Pathway, Proliferation and Signaling. These were reordered into: Radiobiological, Metabolic, Proliferation, Development, Signaling, Cellular component, Pathway and Immune (Supplementary Table 1).

\section{Gene Set Expression Subtype Classification}

We used the algorithm developed by Peng et al. (13) to classify individual tumors given the gene sets of the MsigDB Hallmark collection (9). For a specific patient, the classification was based on the deviation extent of the expression level of genes in a hallmark gene set from the cohort's average values relative to other genes. GSE pre-ranked analysis was used to determine whether the genes from a hallmark gene set were enriched at the top or bottom of each sample's z-ranked gene list. The GSEA algorithm $(14,15)$ was used from the publically available software (GSEA version 4.1.0). For a specific gene set, a tumor sample was classified into one of three distinct groups at FDR > 0.25: "upregulated", "downregulated," or "neutral".

\section{Immune and Stromal Score}

Stromal and immune scores were calculated with the ESTIMATE (estimation of stromal and immune cells in malignant tumor tissues using expression data) algorithm (134). ESTIMATE is an algorithm that uses gene expression signatures to infer the fraction of stromal and immune cells in the tumor samples. The stromal and immune scores predict the level of infiltrating stromal and immune cells in tumor tissue. We downloaded the Stromal and immune scores from the ESTIMATE website (184) of the HNSC, CESC and BRCA patients studied in our research. According to stromal and immune score, all the samples were divided into high and low groups separately.

\section{Survival Analysis}

We evaluated whether the different gene set expression subtypes were associated with the patient's overall survival time. Survival distributions were visualized using Kaplan-Meier curves and univariate Cox $\mathrm{PH}$ model plotted on a forest plot. The significance of the difference between the survival curves was assessed using a log-rank test. Significance for the Cox PH regression was determined using Wald's test. Groups with five or fewer patients were excluded from the survival analysis. Survival analysis was performed using the computer program R (185) and the packages "survival", "survminer", "ggforestplot", "tidyverse" and "ggplot2". 


\section{DATA AVAILABILITY STATEMENT}

Publicly available datasets were analyzed in this study. This data can be found here: https://www.cancer.gov/about-nci/ organization/ccg/research/structural-genomics/tcga.

\section{AUTHOR CONTRIBUTIONS}

Conceptualization, data curation and investigation, SM. Supervision, ID and MR. Writing-original draft, SM. Writing review and editing, ID and MR. All authors discussed the results and contributed to the final manuscript.

\section{REFERENCES}

1. Jemal A, Bray F, Center MM, Ferlay J, Ward E, Forman D. Global Cancer Statistics. CA: Cancer J Clin (2011) 61:69-90. doi: 10.3322/caac.20107

2. Bernier J, Hall E, Giaccia A. Radiation Oncology: A Century of Achievements. Nat Rev Cancer (2004) 4:737-47. doi: 10.1038/nrc1451

3. Yard B, Chie EK, Adams DJ, Peacock C, Abazeed ME. Radiotherapy in the Era of Precision Medicine. Semin Radiat Oncol (2015) 25:227-36. doi: 10.1016/j.semradonc.2015.05.003

4. Baumann M, Krause M, Overgaard J, Debus J, Bentzen SM, Daartz J, et al. Radiation Oncology in the Era of Precision Medicine. Nat Rev Cancer (2016) 16:234-49. doi: 10.1038/nrc.2016.18

5. West CML. Identifying the Radioresponsive Genome for Genomics-Guided Radiotherapy. J Natl Cancer Institute (2020) 113:223-224. doi: 10.1093/jnci/ djaa098

6. Kamran SC, Mouw KW. Applying Precision Oncology Principles in Radiation Oncology. JCO Precis Oncol (2018) 2:PO.18.00034. doi: 10.1200/ PO.18.00034

7. Schaue D, McBride WH. Opportunities and Challenges of Radiotherapy for Treating Cancer. Nat Rev Clin Oncol (2015) 12:527-40. doi: 10.1038/ nrclinonc.2015.120

8. McGraw SA, Garber J, Jänne PA, Lindeman N, Oliver N, Sholl LM, et al. The Fuzzy World of Precision Medicine: Deliberations of a Precision Medicine Tumor Board. Personalized Med (2017) 14:37-50. doi: 10.2217/pme-2016-0074

9. Liberzon A, Birger C, Thorvaldsdóttir H, Ghandi M, Mesirov JP, Tamayo P. The Molecular Signatures Database (MSigDB) Hallmark Gene Set Collection. Cell Syst (2015) 1:417-25. doi: 10.1016/j.cels.2015.12.004

10. Weinstein JN, Collisson EA, Mills GB, Shaw KR, Ozenberger BA, Ellrott K, et al. The Cancer Genome Atlas Pan-Cancer Analysis Project. Nat Genet (2013) 45:1113-20. doi: 10.1038/ng.2764

11. Chmielowski B, Territo M. Manual of Clinical Oncology Vol. 8. Philadelphia: Wolters Kluwer (2017) 8:884.

12. Cohen PA, Jhingran A, Oaknin A, Denny L. Cervical Cancer. Lancet (London England) (2019) 393:169-82. doi: 10.1016/S0140-6736(18)32470-X

13. Peng X, Chen Z, Farshidfar F, Xu X, Lorenzi PL, Wang Y, et al. Molecular Characterization and Clinical Relevance of Metabolic Expression Subtypes in Human Cancers. Cell Rep (2018) 23:255-69. doi: 10.1016/j.celrep.2018. 03.077

14. Mootha VK, Lindgren CM, Eriksson KF, Subramanian A, Sihag S, Lehar J, et al. PGC-1alpha-Responsive Genes Involved in Oxidative Phosphorylation are Coordinately Downregulated in Human Diabetes. Nat Genet (2003) 34:267-73. doi: 10.1038/ng1180

15. Subramanian A, Tamayo P, Mootha VK, Mukherjee S, Ebert BL, Gillette MA, et al. Gene Set Enrichment Analysis: A Knowledge-Based Approach for Interpreting Genome-Wide Expression Profiles. Proc Natl USA (2005) 102:15545-50. doi: 10.1073/pnas.0506580102

16. Saglio G, Kim DW, Issaragrisil S, le Coutre P, Etienne G, Lobo C, et al. Nilotinib Versus Imatinib for Newly Diagnosed Chronic Myeloid Leukemia. New Engl J Med (2010) 362:2251-9. doi: 10.1056/NEJMoa0912614

\section{FUNDING}

This work was supported by the strategic research program "Societal Benefit of Markerless Stereotactic Body Radiotherapy: a Statistical Support based on Quantitative Imaging" (Zwaartepunt, SRP 53, 2019 - 2024) of the research council of the Vrije Universiteit Brussel.

\section{SUPPLEMENTARY MATERIAL}

The Supplementary Material for this article can be found online at: https://www.frontiersin.org/articles/10.3389/fonc.2021.761901/ full\#supplementary-material

17. Long GV, Weber JS, Infante JR, Kim KB, Daud A, Gonzalez R, et al. Overal Survival and Durable Responses in Patients With BRAF V600-Mutant Metastatic Melanoma Receiving Dabrafenib Combined With Trametinib. J Clin Oncol Off J Am Soc Clin Oncol (2016) 34:871-8. doi: 10.1200/ JCO.2015.62.9345

18. Planchard D, Besse B, Groen HJM, Souquet PJ, Quoix E, Baik CS, et al. Dabrafenib Plus Trametinib in Patients With Previously Treated BRAF (V600E)-Mutant Metastatic non-Small Cell Lung Cancer: An Open-Label Multicentre Phase 2 Trial. Lancet Oncol (2016) 17:984-93. doi: 10.1016/ S1470-2045(16)30146-2

19. Shepherd FA, Rodrigues Pereira J, Ciuleanu T, Tan EH, Hirsh V, Thongprasert S, et al. Erlotinib in Previously Treated non-Small-Cell Lung Cancer. N Engl J Med (2005) 353:123-32. doi: 10.1056/NEJMoa050753

20. Lohaus F, Linge A, Tinhofer I, Budach V, Gkika E, Stuschke M, et al. HPV16 DNA Status is a Strong Prognosticator of Loco-Regional Control After Postoperative Radiochemotherapy of Locally Advanced Oropharyngeal Carcinoma: Results From a Multicentre Explorative Study of the German Cancer Consortium Radiation Oncology Group (DKTK-ROG). Radiotherapy Oncol J Eur Soc Ther Radiol Oncol (2014) 113:317-23. doi: 10.1016/j.radonc.2014.11.011

21. Linge A, Schötz U, Löck S, Lohaus F, von Neubeck C, Gudziol V, et al Comparison of Detection Methods for HPV Status as a Prognostic Marker for Loco-Regional Control After Radiochemotherapy in Patients With HNSCC. Radiotherapy Oncol J Eur Soc Ther Radiol Oncol (2018) 127:2735. doi: 10.1016/j.radonc.2017.12.007

22. Wang H, Jiang H, Van De Gucht M, De Ridder M. Hypoxic Radioresistance: Can ROS Be the Key to Overcome it? Cancers (2019) 11:112. doi: 10.3390/ cancers 11010112

23. De Ridder M, Verellen D, Verovski V, Storme G. Hypoxic Tumor Cell Radiosensitization Through Nitric Oxide. Nitric Oxide (2008) 19:164-9. doi: 10.1016/j.niox.2008.04.015

24. Hall EJ, Giaccia AJ. Radiobiology for the Radiologist Vol. 7. Philadelphia: Wolters Kluwer (2012) 7.

25. Deng YR, Chen XJ, Chen W, Wu LF, Jiang HP, Lin D, et al. Sp1 Contributes to Radioresistance of Cervical Cancer Through Targeting G2/M Cell Cycle Checkpoint CDK1. Cancer Manage Res (2019) 11:5835-44. doi: 10.2147/ CMAR.S200907

26. Eriksson D, Löfroth PO, Johansson L, Riklund KA, Stigbrand T. Cell Cycle Disturbances and Mitotic Catastrophes in HeLa Hep2 Cells Following 2.5 to 10 Gy of Ionizing Radiation. Clin Cancer Res an Off J Am Assoc Cancer Res (2007) 13:5501s-8s. doi: 10.1158/1078-0432.CCR-07-0980

27. Cho HJ, Oh YJ, Han SH, Chung HJ, Kim CH, Lee NS, et al. Cdk1 ProteinMediated Phosphorylation of Receptor-Associated Protein 80 (RAP80) Serine 677 Modulates DNA Damage-Induced G2/M Checkpoint and Cell Survival. J Biol Chem (2013) 288:3768-76. doi: 10.1074/jbc.M112.401299

28. Tao Y, Leteur C, Yang C, Zhang P, Castedo M, Pierré A, et al. Radiosensitization by Chir-124, a Selective CHK1 Inhibitor: Effects of P53 and Cell Cycle Checkpoints. Cell Cycle (Georgetown Tex.) (2009) 8:1196205. doi: $10.4161 /$ cc.8.8.8203 
29. Morgan MA, Parsels LA, Zhao L, Parsels JD, Davis MA, Hassan MC, et al. Mechanism of Radiosensitization by the Chk1/2 Inhibitor AZD7762 Involves Abrogation of the G2 Checkpoint and Inhibition of Homologous Recombinational DNA Repair. Cancer Res (2010) 70:4972-81. doi: 10.1158/ 0008-5472.CAN-09-3573

30. Mitchell JB, Choudhuri R, Fabre K, Sowers AL, Citrin D, Zabludoff SD, et al. In Vitro and In Vivo Radiation Sensitization of Human Tumor Cells by a Novel Checkpoint Kinase Inhibitor, AZD7762. Clin Cancer Res an Off J Am Assoc Cancer Res (2010) 16:2076-84. doi: 10.1158/1078-0432.CCR-09-3277

31. Kausar T, Schreiber JS, Karnak D, Parsels LA, Parsels JD, Davis MA, et al. Sensitization of Pancreatic Cancers to Gemcitabine Chemoradiation by WEE1 Kinase Inhibition Depends on Homologous Recombination Repair. Neoplasia (New York N.Y.) (2015) 17:757-766. doi: 10.1016/j.neo.2015.09.006

32. Karnak D, Engelke CG, Parsels LA, Kausar T, Wei D, Robertson JR, et al. Combined Inhibition of Wee1 and PARP1/2 for Radiosensitization in Pancreatic Cancer. Clin Cancer Res an Off J Am Assoc Cancer Res (2014) 20:5085-96. doi: 10.1158/1078-0432.CCR-14-1038

33. Jiang H, Wang H, De Ridder M. Targeting Antioxidant Enzymes as a Radiosensitizing Strategy. Cancer Lett (2018) 438. doi: 10.1016/ j.canlet.2018.09.004

34. Woolston CM, Al-Attar A, Storr SJ, Ellis IO, Morgan DA, Martin SG. Redox Protein Expression Predicts Radiotherapeutic Response in Early-Stage Invasive Breast Cancer Patients. Int J Radiat Oncol Biol Phys (2011) 79:1532-40. doi: 10.1016/j.ijrobp.2010.11.002

35. Zhang B, Wang Y, Su Y. Peroxiredoxins, a Novel Target in Cancer Radiotherapy. Cancer Lett (2009) 286:154-160. doi: 10.1016/j.canlet.2009.04.043

36. Woolston CM, Storr SJ, Ellis IO, Morgan DA, Martin SG. Expression of Thioredoxin System and Related Peroxiredoxin Proteins is Associated With Clinical Outcome in Radiotherapy Treated Early Stage Breast Cancer. Radiotherapy Oncol J Eur Soc Ther Radiol Oncol (2011) 100:308-313. doi: 10.1016/j.radonc.2011.05.029

37. Pouget JP, Frelon S, Ravanat JL, Testard I, Odin F, Cadet J. Formation of Modified DNA Bases in Cells Exposed Either to Gamma Radiation or to High-LET Particles. Radiat Res (2002) 157:589-95. doi: 10.1667/0033-7587 (2002)157[0589:fomdbi]2.0.co;2

38. Sachs RK, Chen PL, Hahnfeldt PJ, Hlatky LR. DNA Damage Caused by Ionizing Radiation. Math Biosci (1992) 112:271-303. doi: 10.1016/00255564(92)90028-u

39. Hanahan D, Weinberg RA. Hallmarks of Cancer: The Next Generation. Cell (2011) 144:646-74. doi: 10.1016/j.cell.2011.02.013

40. Yoshida GJ. Metabolic Reprogramming: The Emerging Concept and Associated Therapeutic Strategies. J Exp Clin Cancer Res CR (2015) 34:111. doi: 10.1186/s13046-015-0221-y

41. Nagao A, Kobayashi M, Koyasu S, Chow CCT, Harada H. HIF-1-Dependent Reprogramming of Glucose Metabolic Pathway of Cancer Cells and Its Therapeutic Significance. Int J Mol Sci (2019) 20:238. doi: 10.3390/ijms20020238

42. Lin J, Xia L, Liang J, Han Y, Wang H, Oyang L, et al. The Roles of Glucose Metabolic Reprogramming in Chemo- and Radio-Resistance. J Exp Clin Cancer Res CR (2019) 38:218. doi: 10.1186/s13046-019-1214-z

43. Pitroda SP, Wakim BT, Sood RF, Beveridge MG, Beckett MA, MacDermed DM, et al. STAT1-Dependent Expression of Energy Metabolic Pathways Links Tumour Growth and Radioresistance to the Warburg Effect. BMC Med (2009) 7:68. doi: 10.1186/1741-7015-7-68

44. McCann E, O'Sullivan J, Marcone S. Targeting Cancer-Cell Mitochondria and Metabolism to Improve Radiotherapy Response. Trans Oncol (2021) 14:100905. doi: 10.1016/j.tranon.2020.100905

45. Tang L, Wei F, Wu Y, He Y, Shi L, Xiong F, et al. Role of Metabolism in Cancer Cell Radioresistance and Radiosensitization Methods. J Exp Clin Cancer Res CR (2018) 37:87. doi: 10.1186/s13046-018-0758-7

46. Vaupel P, Schmidberger H, Mayer A. The Warburg Effect: Essential Part of Metabolic Reprogramming and Central Contributor to Cancer Progression. Int J Radiat Biol (2019) 95:912-9. doi: 10.1080/09553002.2019.1589653

47. Ashton TM, McKenna WG, Kunz-Schughart LA, Higgins GS. Oxidative Phosphorylation as an Emerging Target in Cancer Therapy. Clin Cancer Res an Off J Am Assoc Cancer Res (2018) 24:2482-90. doi: 10.1158/10780432.CCR-17-3070

48. Grasso D, Medeiros HCD, Zampieri LX, Bol V, Danhier P, van Gisbergen MW, et al. Fitter Mitochondria Are Associated With Radioresistance in
Human Head and Neck SQD9 Cancer Cells. Front Pharmacol (2020) 11:263. doi: 10.3389/fphar.2020.00263

49. Viale A, Pettazzoni P, Lyssiotis CA, Ying H, Sánchez N, Marchesini M, et al. Oncogene Ablation-Resistant Pancreatic Cancer Cells Depend on Mitochondrial Function. Nature (2014) 514:628-632. doi: 10.1038/nature13611

50. LeBleu VS, O'Connell JT, Gonzalez Herrera KN, Wikman H, Pantel K, Haigis MC, et al. PGC- $1 \alpha$ Mediates Mitochondrial Biogenesis and Oxidative Phosphorylation in Cancer Cells to Promote Metastasis. Nat Cell Biol (2014) 16:992-1003. doi: 10.1038/ncb3039

51. Lynam-Lennon N, Maher SG, Maguire A, Phelan J, Muldoon C, Reynolds JV, et al. Altered Mitochondrial Function and Energy Metabolism is Associated With a Radioresistant Phenotype in Oesophageal Adenocarcinoma. PloS One (2014) 9:e100738. doi: 10.1371/journal.pone.0100738

52. Swinnen JV, Brusselmans K, Verhoeven G. Increased Lipogenesis in Cancer Cells: New Players, Novel Targets. Curr Opin Clin Nutr Metab Care (2006) 9:358-65. doi: 10.1097/01.mco.0000232894.28674.30

53. Kim W, Son B, Lee S, Do H, Youn B. Targeting the Enzymes Involved in Arachidonic Acid Metabolism to Improve Radiotherapy. Cancer metastasis Rev (2018) 37:213-25. doi: 10.1007/s10555-018-9742-0

54. Aiderus A, Black MA, Dunbier AK. Fatty Acid Oxidation is Associated With Proliferation and Prognosis in Breast and Other Cancers. BMC Cancer (2018) 18:805. doi: 10.1186/s12885-018-4626-9

55. Chuang HY, Lee YP, Lin WC, Lin YH, Hwang JJ. Fatty Acid Inhibition Sensitizes Androgen-Dependent and -Independent Prostate Cancer to Radiotherapy via FASN/NF-кb Pathway. Sci Rep (2019) 9:13284. doi: 10.1038/s41598-019-49486-2

56. Han S, Wei R, Zhang X, Jiang N, Fan M, Huang JH, et al. CPT1A/2Mediated FAO Enhancement-A Metabolic Target in Radioresistant Breast Cancer. Front Oncol (2019) 9:1201. doi: 10.3389/fonc.2019.01201

57. Huang B, Song BL, Xu C. Cholesterol Metabolism in Cancer: Mechanisms and Therapeutic Opportunities. Nat Metab (2020) 2:132-41. doi: 10.1038/ s42255-020-0174-0

58. Poynter JN, Gruber SB, Higgins PD, Almog R, Bonner JD, Rennert HS, et al. Statins and the Risk of Colorectal Cancer. New Engl J Med (2005) 352:218492. doi: 10.1056/NEJMoa043792

59. Rosch PJ, McCully K. Statin Use and Reduced Cancer-Related Mortality New Engl J Med (2013) 368:576. doi: 10.1056/NEJMc1214827

60. Cardwell CR, Hicks BM, Hughes C, Murray LJ. Statin Use After Colorectal Cancer Diagnosis and Survival: A Population-Based Cohort Study. J Clin Oncol Off J Am Soc Clin Oncol (2014) 32:3177-83. doi: 10.1200/JCO.2013.54.4569

61. Larsen SB, Dehlendorff C, Skriver C, Dalton SO, Jespersen CG, Borre M, et al. Postdiagnosis Statin Use and Mortality in Danish Patients With Prostate Cancer. J Clin Oncol Off J Am Soc Clin Oncol (2017) 35:3290-97. doi: 10.1200/JCO.2016.71.8981

62. Sanfilippo KM, Keller J, Gage BF, Luo S, Wang TF, Moskowitz G, et al. Statins Are Associated With Reduced Mortality in Multiple Myeloma. J Clin Oncol Off J Am Soc Clin Oncol (2016) 34:4008-14. doi: 10.1200/JCO.2016.68.3482

63. Nielsen SF, Nordestgaard BG, Bojesen SE. Statin Use and Reduced CancerRelated Mortality. New Engl J Med (2013) 368:576-7. doi: 10.1056/ NEJMc1214827

64. Hutchinson J, Marignol L. Clinical Potential of Statins in Prostate Cancer Radiation Therapy. Anticancer Res (2017) 37:5363-72. doi: 10.21873/ anticanres. 11962

65. Undela K, Srikanth V, Bansal D. Statin Use and Risk of Breast Cancer: A Meta-Analysis of Observational Studies. Breast Cancer Res Treat (2012) 135:261-9. doi: 10.1007/s10549-012-2154-x

66. Shi L, Fang J. Implication of Heme Oxygenase-1 in the Sensitivity of Nasopharyngeal Carcinomas to Radiotherapy. J Exp Clin Cancer Res CR (2008) 27:13. doi: 10.1186/1756-9966-27-13

67. Rochat B. Importance of Influx and Efflux Systems and Xenobiotic Metabolizing Enzymes in Intratumoral Disposition of Anticancer Agents. Curr Cancer Drug Targets (2009) 9:652-74. doi: 10.2174/156800909789056999

68. Zhou F, Zhang J, Li P, Niu F, Wu X, Wang G, et al. Toward a New Age of Cellular Pharmacokinetics in Drug Discovery. Drug Metab Rev (2011) 43:335-45. doi: 10.3109/03602532.2011.560607

69. Michael M, Doherty MM. Drug Metabolism by Tumours: Its Nature, Relevance and Therapeutic Implications. Expert Opin Drug Metab Toxicol (2007) 3:783-803. doi: 10.1517/17425255.3.6.783 
70. Li T, Chiang JY. Bile Acid Signaling in Metabolic Disease and Drug Therapy. Pharmacol Rev (2014) 66:948-83. doi: 10.1124/pr.113.008201

71. Russell DW, Setchell KD. Bile Acid Biosynthesis. Biochemistry (1992) 31:4737-49. doi: 10.1021/bi00135a001

72. Li T, Apte U. Bile Acid Metabolism and Signaling in Cholestasis, Inflammation, and Cancer. Adv Pharmacol (San Diego Calif.) (2015) 74:263-302. doi: 10.1016/bs.apha.2015.04.003

73. Ajouz H, Mukherji D, Shamseddine A. Secondary Bile Acids: An Underrecognized Cause of Colon Cancer. World J Surg Oncol (2014) 12:164. doi: 10.1186/1477-7819-12-164

74. Eaton JE, Talwalkar JA, Lazaridis KN, Gores GJ, Lindor KD. Pathogenesis of Primary Sclerosing Cholangitis and Advances in Diagnosis and Management. Gastroenterology (2013) 145:521-36. doi: 10.1053/j.gastro.2013.06.052

75. Tomiyama Y, Takenaka K, Kodama T, Kawanaka M, Sasaki K, Nishina S, et al. Risk Factors for Survival and the Development of Hepatocellular Carcinoma in Patients With Primary Biliary Cirrhosis. Internal Med (Tokyo Japan) (2013) 52:1553-9. doi: 10.2169/internalmedicine.52.0010

76. Hussaini SH, Pereira SP, Murphy GM, Dowling RH. Deoxycholic Acid Influences Cholesterol Solubilization and Microcrystal Nucleation Time in Gallbladder Bile. Hepatol (Baltimore Md.) (1995) 22:1735-44.

77. Kent LN, Leone G. The Broken Cycle: E2F Dysfunction in Cancer. Nat Rev Cancer (2019) 19:326-38. doi: 10.1038/s41568-019-0143-7

78. Azechi H, Nishida N, Fukuda Y, Nishimura T, Minata M, Katsuma H, et al. Disruption of the P16/Cyclin D1/retinoblastoma Protein Pathway in the Majority of Human Hepatocellular Carcinomas. Oncology (2001) 60:346-54. doi: $10.1159 / 000058531$

79. Di Fiore R, D'Anneo A, Tesoriere G, Vento R. RB1 in Cancer: Different Mechanisms of RB1 Inactivation and Alterations of pRb Pathway in Tumorigenesis. J Cell Physiol (2013) 228:1676-87. doi: 10.1002/jcp.24329

80. Stead E, White J, Faast R, Conn S, Goldstone S, Rathjen J, et al. Pluripotent Cell Division Cycles are Driven by Ectopic Cdk2, Cyclin a/E and E2F Activities. Oncogene (2002) 21:8320-33. doi: 10.1038/sj.onc.1206015

81. Reimer D, Hubalek M, Riedle S, Skvortsov S, Erdel M, Concin N, et al. E2F3a is Critically Involved in Epidermal Growth Factor Receptor-Directed Proliferation in Ovarian Cancer. Cancer Res (2010) 70:4613-23. doi: 10.1158/0008-5472.CAN-09-3551

82. Millour J, de Olano N, Horimoto Y, Monteiro LJ, Langer JK, Aligue R, et al. ATM and P53 Regulate FOXM1 Expression via E2F in Breast Cancer Epirubicin Treatment and Resistance. Mol Cancer Ther (2011) 10:104658. doi: 10.1158/1535-7163.MCT-11-0024

83. Santos M, Martínez-Fernández M, Dueñas M, García-Escudero R, Alfaya B, Villacampa F, et al. In Vivo Disruption of an Rb-E2F-Ezh2 Signaling Loop Causes Bladder Cancer. Cancer Res (2014) 74:6565-77. doi: 10.1158/00085472.CAN-14-1218

84. Kaseb AO, Chinnakannu K, Chen D, Sivanandam A, Tejwani S, Menon M, et al. Androgen Receptor and E2F-1 Targeted Thymoquinone Therapy for Hormone-Refractory Prostate Cancer. Cancer Res (2007) 67:7782-88. doi: 10.1158/0008-5472.CAN-07-1483

85. Chen L, Kurtyka CA, Welsh EA, Rivera JI, Engel BE, Muñoz-Antonia T, et al. Early2 Factor (E2F) Deregulation is a Prognostic and Predictive Biomarker in Lung Adenocarcinoma. Oncotarget (2016) 7:82254-65. doi: 10.18632/oncotarget. 12672

86. Yao H, Lu F, Shao Y. The E2F Family as Potential Biomarkers and Therapeutic Targets in Colon Cancer. PeerJ (2020) 8:e8562. doi: 10.7717/peerj.8562

87. Tazawa $H$, Tsuchiya N, Izumiya $M$, Nakagama H. Tumor-Suppressive miR34a Induces Senescence-Like Growth Arrest Through Modulation of the E2F Pathway in Human Colon Cancer Cells. Proc Natl Acad Sci United States America (2007) 104:15472-7. doi: 10.1073/pnas.0707351104

88. Dumontet C, Jordan MA. Microtubule-Binding Agents: A Dynamic Field of Cancer Therapeutics. Nat Rev Drug Discov (2010) 9:790-803. doi: 10.1038/nrd3253

89. Bernabeu E, Cagel M, Lagomarsino E, Moretton M, Chiappetta DA. Paclitaxel: What has Been Done and the Challenges Remain Ahead. Int J Pharmaceutics (2017) 526:474-95. doi: 10.1016/j.ijpharm.2017.05.016

90. Tischer J, Gergely F. Anti-Mitotic Therapies in Cancer. J Cell Biol (2019) 218:10-11. doi: 10.1083/jcb.201808077

91. Penna LS, Henriques JAP, Bonatto D. Anti-Mitotic Agents: Are They Emerging Molecules for Cancer Treatment? Pharmacol Ther (2017) 173:67-82. doi: 10.1016/j.pharmthera.2017.02.007
92. Ilagan E, Manning BD. Emerging Role of mTOR in the Response to Cancer Therapeutics. Trends Cancer (2016) 2:241-51. doi: 10.1016/j.trecan. 2016.03.008

93. Guri Y, Hall MN. mTOR Signaling Confers Resistance to Targeted Cancer Drugs. Trends Cancer (2016) 2. doi: 10.1016/j.trecan.2016.10.006

94. Saxton RA, Sabatini DM. mTOR Signaling in Growth, Metabolism, and Disease. Cell (2017) 168:960-76. doi: 10.1016/j.cell.2017.02.004

95. Liu GY, Sabatini DM. mTOR at the Nexus of Nutrition, Growth, Ageing and Disease. Nat Rev Mol Cell Biol (2020) 21:183-203. doi: 10.1038/s41580-0190199-y

96. Woo Y, Lee HJ, Jung YM, Jung YJ. mTOR-Mediated Antioxidant Activation in Solid Tumor Radioresistance. J Oncol (2019) 2019:5956867. doi: 10.1155/ 2019/5956867

97. Freudlsperger C, Horn D, Weißfuß S, Weichert W, Weber KJ, Saure D, et al. Phosphorylation of AKT(Ser473) Serves as an Independent Prognostic Marker for Radiosensitivity in Advanced Head and Neck Squamous Cell Carcinoma. Int J Cancer (2015) 136:2775-85. doi: 10.1002/ijc.29328

98. Avan A, Narayan R, Giovannetti E, Peters GJ. Role of Akt Signaling in Resistance to DNA-Targeted Therapy. World J Clin Oncol (2016) 7:352-69. doi: 10.5306/wjco.v7.i5.352

99. Chen H, Liu H, Qing G. Targeting Oncogenic Myc as a Strategy for Cancer Treatment. Signal Transduction Targeted Ther (2018) 3:5. doi: 10.1038/ s41392-018-0008-7

100. Allen-Petersen BL, Sears RC. Mission Possible: Advances in MYC Therapeutic Targeting in Cancer. BioDrugs Clin Immunotherapeutics Biopharmaceuticals Gene Ther (2019) 33:539-53. doi: 10.1007/s40259-019-00370-5

101. Luoto KR, Meng AX, Wasylishen AR, Zhao H, Coackley CL, Penn LZ, et al. Tumor Cell Kill by C-MYC Depletion: Role of MYC-Regulated Genes That Control DNA Double-Strand Break Repair. Cancer Res (2010) 70:8748-59. doi: 10.1158/0008-5472.CAN-10-0944

102. Wang R, Chen DQ, Huang JY, Zhang K, Feng B, Pan BZ, et al. Acquisition of Radioresistance in Docetaxel-Resistant Human Lung Adenocarcinoma Cells is Linked With Dysregulation of miR-451/C-Myc-Survivin/Rad-51 Signaling. Oncotarget (2014) 5:6113-29. doi: 10.18632/oncotarget.2176

103. Gudkov AV, Komarova EA. The Role of P53 in Determining Sensitivity to Radiotherapy. Nat Rev Cancer (2003) 3:117-29. doi: 10.1038/nrc992

104. Stiewe T. The P53 Family in Differentiation and Tumorigenesis. Nat Rev Cancer (2007) 7:165-8. doi: 10.1038/nrc2072

105. Zhang J, Shen L, Sun LQ. The Regulation of Radiosensitivity by P53 and its Acetylation. Cancer Lett (2015) 363:108-18. doi: 10.1016/j.canlet.2015. 04.015

106. Zhang Y, Weinberg RA. Epithelial-To-Mesenchymal Transition in Cancer: Complexity and Opportunities. Front Med (2018) 12:361-73. doi: 10.1007/ s11684-018-0656-6

107. Theys J, Jutten B, Habets R, Paesmans K, Groot AJ, Lambin P, et al. ECadherin Loss Associated With EMT Promotes Radioresistance in Human Tumor Cells. Radiotherapy Oncol J Eur Soc Ther Radiol Oncol (2011) 99:3927. doi: 10.1016/j.radonc.2011.05.044

108. Nantajit D, Lin D, Li JJ. The Network of Epithelial-Mesenchymal Transition: Potential New Targets for Tumor Resistance. J Cancer Res Clin Oncol (2015) 141:1697-713. doi: 10.1007/s00432-014-1840-y

109. Zhou S, Zhang M, Zhou C, Wang W, Yang H, Ye W. The Role of EpithelialMesenchymal Transition in Regulating Radioresistance. Crit Rev oncology/ hematology (2020) 150:102961. doi: 10.1016/j.critrevonc.2020.102961

110. Michmerhuizen AR, Spratt DE, Pierce LJ, Speers CW. ARe We There Yet? Understanding Androgen Receptor Signaling in Breast Cancer. NPJ Breast Cancer (2020) 6:47. doi: 10.1038/s41523-020-00190-9

111. Munoz J, Wheler JJ, Kurzrock R. Androgen Receptors Beyond Prostate Cancer: An Old Marker as a New Target. Oncotarget (2015) 6:592-603. doi: 10.18632/oncotarget.2831

112. Spratt DE, Evans MJ, Davis BJ, Doran MG, Lee MX, Shah N, et al. Androgen Receptor Upregulation Mediates Radioresistance After Ionizing Radiation. Cancer Res (2015) 75:4688-96. doi: 10.1158/0008-5472.CAN-15-0892

113. Rong C, Meinert É.F.R.C., Hess J. Estrogen Receptor Signaling in Radiotherapy: From Molecular Mechanisms to Clinical Studies. Int J Mol Sci (2018) 19:713. doi: 10.3390/ijms19030713

114. Gurtner K, Kryzmien Z, Koi L, Wang M, Benes CH, Hering S, et al. Radioresistance of KRAS/TP53-Mutated Lung Cancer can be Overcome by 
Radiation Dose Escalation or EGFR Tyrosine Kinase Inhibition. vivo. Int $J$ Cancer (2020) 147:472-7. doi: 10.1002/ijc.32598

115. Bernhard EJ, Stanbridge EJ, Gupta S, Gupta AK, Soto D, Bakanauskas VJ, et al. Direct Evidence for the Contribution of Activated N-Ras and K-Ras Oncogenes to Increased Intrinsic Radiation Resistance in Human Tumor Cell Lines. Cancer Res (2000) 60:6597-600.

116. Wang M, Han J, Marcar L, Black J, Liu Q, Li X, et al. Radiation Resistance in KRAS-Mutated Lung Cancer Is Enabled by Stem-Like Properties Mediated by an Osteopontin-EGFR Pathway. Cancer Res (2017) 77:2018-28. doi: 10.1158/0008-5472.CAN-16-0808

117. Cassidy RJ, Zhang X, Patel PR, Shelton JW, Escott CE, Sica GL, et al. NextGeneration Sequencing and Clinical Outcomes of Patients With Lung Adenocarcinoma Treated With Stereotactic Body Radiotherapy. Cancer (2017) 123:3681-90. doi: 10.1002/cncr.30794

118. Mak RH, Hermann G, Lewis JH, Aerts HJ, Baldini EH, Chen AB, et al. Outcomes by Tumor Histology and KRAS Mutation Status After Lung Stereotactic Body Radiation Therapy for Early-Stage non-Small-Cell Lung Cancer. Clin Lung Cancer (2015) 16:24-32. doi: 10.1016/j.cllc.2014.09.005

119. Garcia-Aguilar J, Chen Z, Smith DD, Li W, Madoff RD, Cataldo P, et al. Identification of a Biomarker Profile Associated With Resistance to Neoadjuvant Chemoradiation Therapy in Rectal Cancer. Ann Surg (2011) 254:486-92. doi: 10.1097/SLA.0b013e31822b8cfa

120. Skoulidis F, Byers LA, Diao L, Papadimitrakopoulou VA, Tong P, Izzo J, et al. Co-Occurring Genomic Alterations Define Major Subsets of KRAS-Mutant Lung Adenocarcinoma With Distinct Biology, Immune Profiles, and Therapeutic Vulnerabilities. Cancer Discov (2015) 5:860-77. doi: 10.1158/ 2159-8290.CD-14-1236

121. Jiang W, Xiang L, Pei X, He T, Shen X, Wu X, et al. Mutational Analysis of KRAS and its Clinical Implications in Cervical Cancer Patients. J gynecologic Oncol (2018) 29:e4. doi: 10.3802/jgo.2018.29.e4

122. Liu S, Ren J, Ten Dijke P. Targeting Tgf $\beta$ Signal Transduction for Cancer Therapy. Signal Transduction Targeted Ther (2021) 6:8. doi: 10.1038/s41392020-00436-9

123. Farhood B, Khodamoradi E, Hoseini-Ghahfarokhi M, Motevaseli E, Mirtavoos-Mahyari H, Eleojo Musa A, et al. TGF- $\beta$ in Radiotherapy: Mechanisms of Tumor Resistance and Normal Tissues Injury. Pharmacol Res (2020) 155:104745. doi: 10.1016/j.phrs.2020.104745

124. Dancea HC, Shareef MM, Ahmed MM. Role of Radiation-Induced TGF-Beta Signaling in Cancer Therapy. Mol Cell Pharmacol (2009) 1:44-56. doi: 10.4255/mcpharmacol.09.06

125. González-Mariscal L, Miranda J, Gallego-Gutiérrez H, Cano-Cortina M, Amaya E. Relationship Between Apical Junction Proteins, Gene Expression and Cancer. Biochim Biophys Acta Biomembranes (2020) 1862:183278. doi: 10.1016/j.bbamem.2020.183278

126. Feizi A, Gatto F, Uhlen M, Nielsen J. Human Protein Secretory Pathway Genes are Expressed in a Tissue-Specific Pattern to Match Processing Demands of the Secretome. NPJ Syst Biol Appl (2017) 3:22. doi: 10.1038/s41540-017-0021-4

127. Uhlén M, Fagerberg L, Hallström BM, Lindskog C, Oksvold P, Mardinoglu A, et al. Proteomics. Tissue-Based Map of the Human Proteome. Sci (New York N.Y.) (2015) 347:1260419. doi: 10.1126/science.1260419

128. Pohlschröder M, Hartmann E, Hand NJ, Dilks K, Haddad A. Diversity and Evolution of Protein Translocation. Annu Rev Microbiol (2005) 59:91-111. doi: 10.1146/annurev.micro.59.030804.121353

129. Wang M, Kaufman RJ. Protein Misfolding in the Endoplasmic Reticulum as a Conduit to Human Disease. Nature (2016) 529:326-35. doi: 10.1038/ nature 17041

130. Bochet L, Meulle A, Imbert S, Salles B, Valet P, Muller C. Cancer-Associated Adipocytes Promotes Breast Tumor Radioresistance. Biochem Biophys Res Commun (2011) 411:102-6. doi: 10.1016/j.bbrc.2011.06.101

131. Zhang F, Liu S. Mechanistic Insights of Adipocyte Metabolism in Regulating Breast Cancer Progression. Pharmacol Res (2020) 155:104741. doi: 10.1016/ j.phrs.2020.104741

132. Wang Y, Liu ZG, Yuan H, Deng W, Li J, Huang Y, et al. The Reciprocity Between Radiotherapy and Cancer Immunotherapy. Clin Cancer Res an Off $J$ Am Assoc Cancer Res (2019) 25:1709-17. doi: 10.1158/1078-0432.CCR-18-2581

133. Locy H, de Mey S, de Mey W, De Ridder M, Thielemans K, Maenhout SK. Immunomodulation of the Tumor Microenvironment: Turn Foe Into Friend. Front Immunol (2018) 9:2909. doi: 10.3389/fimmu.2018.02909
134. Yoshihara K, Shahmoradgoli M, Martínez E, Vegesna R, Kim H, TorresGarcia W, et al. Inferring Tumour Purity and Stromal and Immune Cell Admixture From Expression Data. Nat Commun (2013) 4:2612. doi: $10.1038 /$ ncomms 3612

135. Chen HHW, Kuo MT. Improving Radiotherapy in Cancer Treatment: Promises and Challenges. Oncotarget (2017) 8:62742-58. doi: 10.18632/ oncotarget.18409

136. Buckley AM, Lynam-Lennon N, O'Neill H, O'Sullivan J. Targeting Hallmarks of Cancer to Enhance Radiosensitivity in Gastrointestinal Cancers. Nat Rev Gastroenterol Hepatol (2020) 17:298-313. doi: 10.1038/ s41575-019-0247-2

137. Li LT, Jiang G, Chen Q, Zheng JN. Ki67 is a Promising Molecular Target in the Diagnosis of Cancer (Review). Mol Med Rep (2015) 11:1566-72. doi: $10.3892 / \mathrm{mmr} .2014 .2914$

138. Karamitopoulou E, Perentes E, Tolnay M, Probst A. Prognostic Significance of MIB-1, P53, and Bcl-2 Immunoreactivity in Meningiomas. Hum Pathol (1998) 29:140-5. doi: 10.1016/s0046-8177(98)90224-6

139. Zeng M, Zhou J, Wen L, Zhu Y, Luo Y, Wang W. The Relationship Between the Expression of Ki-67 and the Prognosis of Osteosarcoma. BMC Cancer (2021) 21:210. doi: 10.1186/s12885-021-07880-y

140. He Y, Wang N, Zhou X, Wang J, Ding Z, Chen X, et al. Prognostic Value of Ki67 in BCG-Treated non-Muscle Invasive Bladder Cancer: A Meta-Analysis and Systematic Review. BMJ Open (2018) 8:e019635. doi: 10.1136/bmjopen2017-019635

141. Klöppel G, La Rosa S. Ki67 Labeling Index: Assessment and Prognostic Role in Gastroenteropancreatic Neuroendocrine Neoplasms. Virchows Arch (2018) 472:341-9. doi: 10.1007/s00428-017-2258-0

142. James CD, Morgan IM, Bristol ML. The Relationship Between EstrogenRelated Signaling and Human Papillomavirus Positive Cancers. Pathogens (2020) 9:403. doi: 10.3390/pathogens 9050403

143. Hellberg D. Sex Steroids and Cervical Cancer. Anticancer Res (2012) 32:3045-54.

144. International Collaboration of Epidemiological Studies of Cervical Cancer. Cervical Carcinoma and Reproductive Factors: Collaborative Reanalysis of Individual Data on 16,563 Women With Cervical Carcinoma and 33,542 Women Without Cervical Carcinoma From 25 Epidemiological Studies. Int $J$ Cancer (2006) 119:1108-24. doi: 10.1002/ijc.21953

145. Roura E, Travier N, Waterboer T, de Sanjosé S, Bosch FX, Pawlita M, et al. The Influence of Hormonal Factors on the Risk of Developing Cervical Cancer and Pre-Cancer: Results From the EPIC Cohort. PloS One (2016) 11: e0147029. doi: 10.1371/journal.pone.0147029

146. Muñoz N, Castellsagué X, Berrington de González A, Gissmann L. Chapter 1: HPV in the Etiology of Human Cancer. Vaccine (2006) 24(Suppl 3):S3/1-10. doi: 10.1016/j.vaccine.2006.05.115

147. Appleby P, Beral V, Berrington de González A, Colin D, Franceschi S, Goodhill A, et al. Cervical Cancer and Hormonal Contraceptives: Collaborative Reanalysis of Individual Data for 16,573 Women With Cervical Cancer and 35,509 Women Without Cervical Cancer From 24 Epidemiological Studies. Lancet (2007) 370:1609-21. doi: 10.1016/s01406736(07)61684-5

148. Zhang Y, Zhang Z. The History and Advances in Cancer Immunotherapy: Understanding the Characteristics of Tumor-Infiltrating Immune Cells and Their Therapeutic Implications. Cell Mol Immunol (2020) 17:807-21. doi: 10.1038/s41423-020-0488-6

149. Pages F, Kirilovsky A, Mlecnik B, Asslaber M, Tosolini M, Bindea G, et al. In Situ Cytotoxic and Memory T Cells Predict Outcome in Patients With EarlyStage Colorectal Cancer. J Clin Oncol (2009) 27:5944-51. doi: 10.1200/ jco.2008.19.6147

150. Galon J, Costes A, Sanchez-Cabo F, Kirilovsky A, Mlecnik B, Lagorce-Pages C, et al. Type, Density, and Location of Immune Cells Within Human Colorectal Tumors Predict Clinical Outcome. Science (2006) 313:1960-4. doi: $10.1126 /$ science.1129139

151. Pages F, Galon J, Dieu-Nosjean MC, Tartour E, Sautes-Fridman C, Fridman WH. Immune Infiltration in Human Tumors: A Prognostic Factor That Should Not be Ignored. Oncogene (2010) 29:1093-102. doi: 10.1038/ onc.2009.416

152. Balkwill FR, Capasso M, Hagemann T. The Tumor Microenvironment at a Glance. J Cell Sci (2012) 125:5591-6. doi: 10.1242/jcs.116392 
153. Wondergem NE, Nauta IH, Muijlwijk T, Leemans CR, van de Ven R. The Immune Microenvironment in Head and Neck Squamous Cell Carcinoma: On Subsets and Subsites. Curr Oncol Rep (2020) 22:81. doi: 10.1007/s11912020-00938-3

154. Ohno A, Iwata T, Katoh Y, Taniguchi S, Tanaka K, Nishio H, et al. TumorInfiltrating Lymphocytes Predict Survival Outcomes in Patients With Cervical Cancer Treated With Concurrent Chemoradiotherapy. Gynecol Oncol (2020) 159:329-34. doi: 10.1016/j.ygyno.2020.07.106

155. Piersma SJ, Jordanova ES, van Poelgeest MI, Kwappenberg KM, van der Hulst JM, Drijfhout JW, et al. High Number of Intraepithelial CD8+ TumorInfiltrating Lymphocytes is Associated With the Absence of Lymph Node Metastases in Patients With Large Early-Stage Cervical Cancer. Cancer Res (2007) 67:354-61. doi: 10.1158/0008-5472.can-06-3388

156. Bethwaite PB, Holloway LJ, Thornton A, Delahunt B. Infiltration by Immunocompetent Cells in Early Stage Invasive Carcinoma of the Uterine Cervix: A Prognostic Study. Pathology (1996) 28:321-7. doi: 10.1080/ 00313029600169274

157. Swoboda A, Nanda R. Immune Checkpoint Blockade for Breast Cancer. Cancer Treat Res (2018) 173:155-65. doi: 10.1007/978-3-319-70197-4_10

158. Waldman AD, Fritz JM, Lenardo MJ. A Guide to Cancer Immunotherapy: From T Cell Basic Science to Clinical Practice. Nat Rev Immunol (2020) 20:651-68. doi: 10.1038/s41577-020-0306-5

159. Amundson SA, Do KT, Vinikoor LC, Lee RA, Koch-Paiz CA, Ahn J, et al. Integrating Global Gene Expression and Radiation Survival Parameters Across the 60 Cell Lines of the National Cancer Institute Anticancer Drug Screen. Cancer Res (2008) 68:415-24. doi: 10.1158/0008-5472.CAN07-2120

160. Torres-Roca JF, Eschrich S, Zhao H, Bloom G, Sung J, McCarthy S, et al. Prediction of Radiation Sensitivity Using a Gene Expression Classifier. Cancer Res (2005) 65:7169-76. doi: 10.1158/0008-5472. CAN-05-0656

161. Ahmed KA, Chinnaiyan P, Fulp WJ, Eschrich S, Torres-Roca JF, Caudell JJ. The Radiosensitivity Index Predicts for Overall Survival in Glioblastoma. Oncotarget (2015) 6:34414-22. doi: 10.18632/oncotarget.5437

162. Eschrich SA, Pramana J, Zhang H, Zhao H, Boulware D, Lee JH, et al. A Gene Expression Model of Intrinsic Tumor Radiosensitivity: Prediction of Response and Prognosis After Chemoradiation. Int J Radiat Oncol Biol Phys (2009) 75:489-96. doi: 10.1016/j.ijrobp.2009.06.014

163. Strom T, Hoffe SE, Fulp W, Frakes J, Coppola D, Springett GM, et al. Radiosensitivity Index Predicts for Survival With Adjuvant Radiation in Resectable Pancreatic Cancer. Radiotherapy Oncol J Eur Soc Ther Radiol Oncol (2015) 117:159-64. doi: 10.1016/j.radonc.2015.07.018

164. Shedden K, Taylor JM, Enkemann SA, Tsao MS, Yeatman TJ, Gerald WL, et al. Gene Expression-Based Survival Prediction in Lung Adenocarcinoma: A Multi-Site, Blinded Validation Study. Nat Med (2008) 14:822-7. doi: $10.1038 / \mathrm{nm} .1790$

165. Eschrich SA, Fulp WJ, Pawitan Y, Foekens JA, Smid M, Martens JW, et al. Validation of a Radiosensitivity Molecular Signature in Breast Cancer. Clin Cancer Res an Off J Am Assoc Cancer Res (2012) 18:5134-43. doi: 10.1158/ 1078-0432.CCR-12-0891

166. Kim HS, Kim SC, Kim SJ, Park CH, Jeung HC, Kim YB, et al. Identification of a Radiosensitivity Signature Using Integrative Metaanalysis of Published Microarray Data for NCI-60 Cancer Cells. BMC Genomics (2012) 13:348. doi: $10.1186 / 1471-2164-13-348$

167. Story MD, Durante M. Radiogenomics. Med Phys (2018) 45:e1111-22. doi: $10.1002 / \mathrm{mp} .13064$

168. Gao WZ, Guo LM, Xu TQ, Yin YH, Jia F. Identification of a Multidimensional Transcriptome Signature for Survival Pprediction of Postoperative Glioblastoma Multiforme Patients. J Transl Med (2018) 16:368. doi: 10.1186/s12967-018-1744-8

169. Minata M, Audia A, Shi J, Lu S, Bernstock J, Pavlyukov MS, et al. Phenotypic Plasticity of Invasive Edge Glioma Stem-Like Cells in Response to Ionizing Radiation. Cell Rep (2019) 26:1893-905.e1897. doi: 10.1016/ j.celrep.2019.01.076

170. Kocakavuk E, Anderson KJ, Varn FS, Johnson KC, Amin SB, Sulman EP, et al. Radiotherapy Is Associated With a Deletion Signature That Contributes to Poor Outcomes in Patients With Cancer. Nat Genet (2021) 53:1088-96. doi: 10.1038/s41588-021-00874-3

171. Feng Y, Li G, Shi Z, Yan X, Wang Z, Jiang H, et al. A Novel Methylation Signature Predicts Radiotherapy Sensitivity in Glioma. Sci Rep (2020) 10:20406. doi: 10.1038/s41598-020-77259-9

172. Li S, Shi J, Gao H, Yuan Y, Chen Q, Zhao Z, et al. Identification of a Gene Signature Associated With Radiotherapy and Prognosis in Gliomas. Oncotarget (2017) 8:88974-87. doi: 10.18632/oncotarget.21634

173. Kim Y, Varn FS, Park SH, Yoon BW, Park HR, Lee C, et al. Perspective of Mesenchymal Transformation in Glioblastoma. Acta Neuropathol Commun (2021) 9:50. doi: 10.1186/s40478-021-01151-4

174. Scott JG, Berglund A, Schell MJ, Mihaylov I, Fulp WJ, Yue B, et al. A Genome-Based Model for Adjusting Radiotherapy Dose (GARD): A Retrospective, Cohort-Based Study. Lancet Oncol (2017) 18:202-11. doi: 10.1016/s1470-2045(16)30648-9

175. Willers H, Keane FK, Kamran SC. Toward a New Framework for Clinical Radiation Biology. Hematology/oncology Clinics North America (2019) 33:929-45. doi: 10.1016/j.hoc.2019.07.001

176. Kamran SC, Lennerz JK, Margolis CA, Liu D, Reardon B, Wankowicz SA, et al. Integrative Molecular Characterization of Resistance to Neoadjuvant Chemoradiation in Rectal Cancer. Clin Cancer Res an Off J Am Assoc Cancer Res (2019) 25:5561-71. doi: 10.1158/1078-0432.CCR-19-0908

177. Zhao SG, Chang SL, Spratt DE, Erho N, Yu M, Ashab HA, et al. Development and Validation of a 24-Gene Predictor of Response to Postoperative Radiotherapy in Prostate Cancer: A Matched, Retrospective Analysis. Lancet Oncol (2016) 17:1612-20. doi: 10.1016/S1470-2045(16)30491-0

178. Faubert B, Solmonson A, DeBerardinis RJ. Metabolic Reprogramming and Cancer Progression. Science (2020) 368:eaaw5473. doi: 10.1126/ science.aaw5473

179. Chen WS, Townsend JP, Yu JB. Radiation-Specific Clinical Data Should Be Included in Existing Large-Scale Genomic Datasets. Int J Radiat Oncol Biol Phys (2017) 98:8-10. doi: 10.1016/j.ijrobp.2017.01.023

180. Tin Kam H. The Random Subspace Method for Constructing Decision Forests. IEEE Trans Pattern Anal Mach Intell (1998) 20:832-44. doi: 10.1109/ 34.709601

181. Cerami E, Gao J, Dogrusoz U, Gross BE, Sumer SO, Aksoy BA, et al. The Cbio Cancer Genomics Portal: An Open Platform for Exploring Multidimensional Cancer Genomics Data. Cancer Discov (2012) 2:401-4. doi: 10.1158/2159-8290.CD-12-0095

182. Gao J, Aksoy BA, Dogrusoz U, Dresdner G, Gross B, Sumer SO, et al. Integrative Analysis of Complex Cancer Genomics and Clinical Profiles Using the Cbioportal. Sci Signaling (2013) 6:pl1. doi: 10.1126/scisignal. 2004088

183. GDC. Available at: https://portal.gdc.cancer.gov/.

184. ESTIMATE: Home. Available at: https://bioinformatics.mdanderson.org/ estimate/.

185. Team, R.C. R -A Language and Environment for Statistical Computing. In: $R$ - Foundation for Statistical Computing (2020). Available at: https://www.Rproject.org/.

Conflict of Interest: The authors declare that the research was conducted in the absence of any commercial or financial relationships that could be construed as a potential conflict of interest.

Publisher's Note: All claims expressed in this article are solely those of the authors and do not necessarily represent those of their affiliated organizations, or those of the publisher, the editors and the reviewers. Any product that may be evaluated in this article, or claim that may be made by its manufacturer, is not guaranteed or endorsed by the publisher.

Copyright (c) 2021 de Mey, Dufait and De Ridder. This is an open-access article distributed under the terms of the Creative Commons Attribution License (CC BY). The use, distribution or reproduction in other forums is permitted, provided the original author(s) and the copyright owner(s) are credited and that the original publication in this journal is cited, in accordance with accepted academic practice. No use, distribution or reproduction is permitted which does not comply with these terms. 